Total word count: 12037

Word count without, tables, figure captions and references: 8109

Word count without abstract, tables, figure captions and references: 7929

\title{
Raw metal needs and supply risks for the development of wind energy in Germany until 2050
}

\begin{abstract}
Facilitated by the environmental goals set by the government, wind turbines will be one of the main pillars of the future electricity production in Germany. In this paper, a comprehensive assessment of the future metallic raw material requirements for the development of the German wind energy sector was conducted, which is closely based on the current and future market conditions. Copper and dysprosium are identified as the most critical materials since they face the possibility of supply bottlenecks while being fundamental to the functionality of wind turbines. While the cumulative demand for copper may require $0.2 \%$ of the current known reserves, the demand for dysprosium may reach up to $0.6 \%$ of the reserve levels. Both metals clearly exceed the allocations for renewable energy technologies in Germany and would face strong competition from other sectors in securing raw materials. Although recycling is able to reduce the bottleneck risks, it does not completely mitigate them. More efforts are therefore required to improve material efficiency by means of alternative turbine designs, efficient productioß, techniques, highly reliable components and material substitution.
\end{abstract}

Keywords: Wind turbine; German energy transformation; material demand; supply availability; recycling
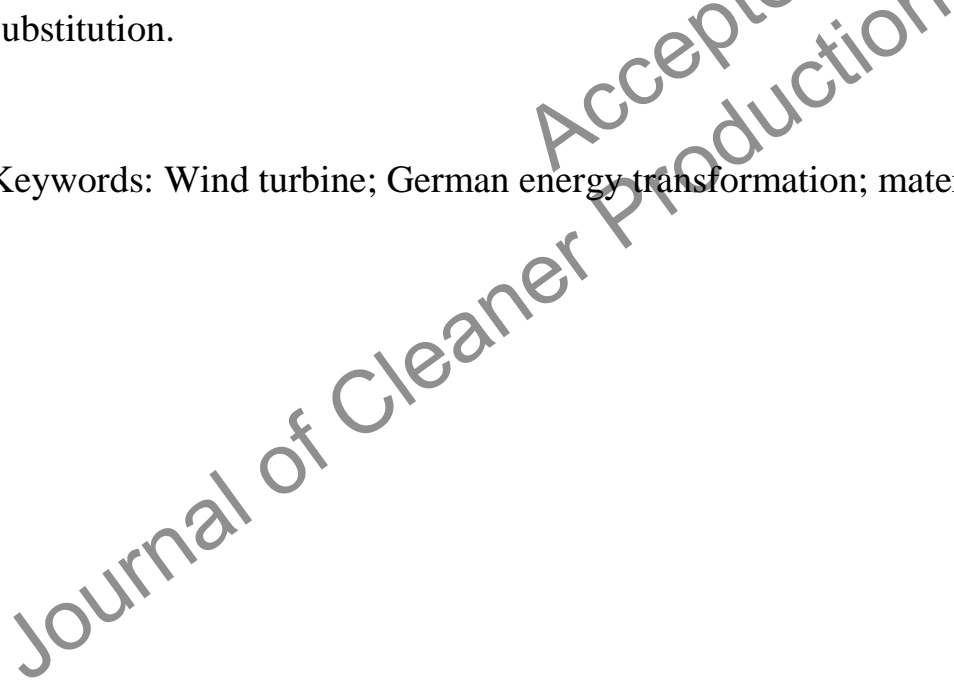


\section{Introduction}

The Renewable-Energy-Sources-Act was formed in Germany in order to grant priority to renewable energy sources and to facilitate a sustainable development of the energy supply (BMWi 2014). Since then, the renewable share in the total electricity production has been increasing gradually from $7 \%$ in 2001 to $32 \%$ in 2017 (BMWi 2018a). Various studies, such as (Nitsch 2014) and (Prognos AG, EWI, GWS 2014), have been published to prove the technical viability of a future energy system with high shares of renewable energy in Germany. Not only are the national goals of at least $80 \%$ of renewable electricity production possible to be achieved, but a 100\% renewable energy system is also technically plausible (Henning and Palzer 2012). These studies share the common fact that wind turbines will be one of the main pillars of electricity production, thus emphasizing their importance in shaping the framework of the future energy system in Germany.

Over the past years, wind turbines have been becoming larger and more powerful, as can be seen in Figure 1 . Studies such as (DONG Energy 2008) and (EWEA 2011) project that 20 MW turbines with rotor diameter of over $250 \mathrm{~m}$ would be available to the market by 2050 . Moreover, the industry is shifting from the classic "Danish concept" wind turbines, based on constant speed and directly grid-connected induction generators, to the variable speed generators that include more reliable synchronous generators with permanent magnets (PM) in order to accommodate the need for multi-megawatt scaled turbines. The six most common drive-train systems currently applied in Germany are listed in Table 1. The drive-trains can generally be divided into two categories, namely generators with permanent magnets (PMs) and without, which in exchange have more amount of copper windings. In this term, copper and PMs are substitutes in demand. A large-scale deployment of wind turbines in the future implies significant raw material requirements. With the presence of critical metals such as rare-earth-elements (REE) in the PM, increased demand might lead to supply risks which could dampen the cost reductions of wind turbines and thus disrupting a wide-scale deployment. An early detection of possible supply bottlenecks is a precondition to ensuring an economical large-scale deployment in the future.

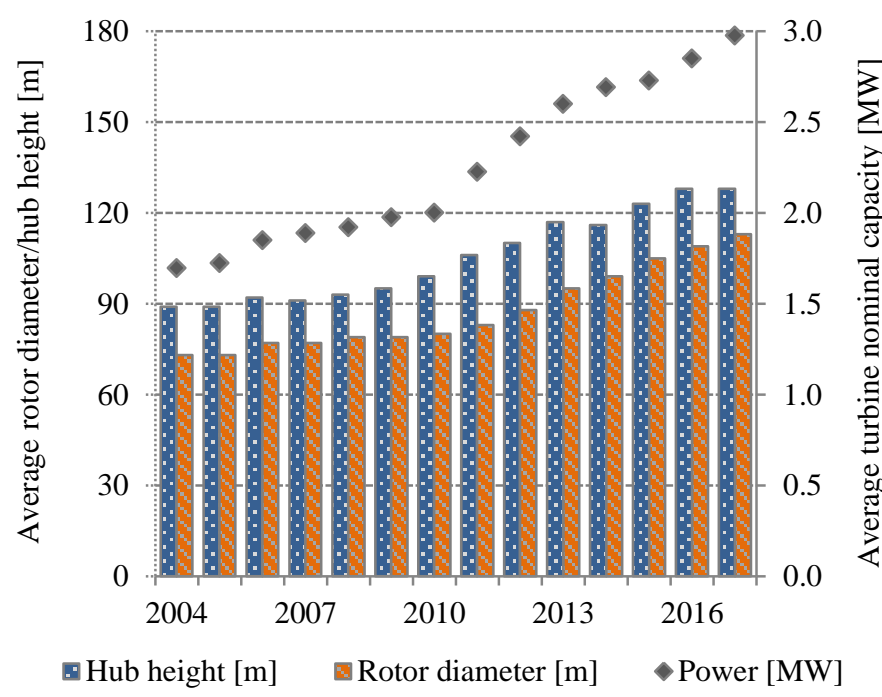

Figure 1: Historical development of average hub height, rotor diameter and nominal power of wind turbines installed in Germany (Fraunhofer IEE 2018) 
Table 1: Common drive train systems installed in Germany and some of their notable manufacturers. The pseudo directdrive and superconducting direct-drive drive-train systems are future concepts that are still in research.

\begin{tabular}{ccc}
\hline Drive-train systems & Acronym & Notable manufacturers \\
\hline Electrically Excited Synchronous Generator Direct-Drive & EESG-DD & Enercon \\
Permanent Magnet Synchronous Generator Direct-Drive & PMSG-DD & Siemens, Vensys \\
Permanent Magnet Synchronous Generator Middle Speed & PMSG-MS & Areva \\
Permanent Magnet Synchronous Generator High Speed & PMSG-HS & Vestas \\
Doubly-Fed Induction Generator & DFIG & Nordex, GE, Senvion, Gamesa \\
Squirrel Cage Induction Generator (Variable Speed) & SCIG & Vestas, Senvion, Siemens \\
Pseudo direct-drive & PDD & - \\
Superconducting direct-drive & SDD & - \\
\hline
\end{tabular}

The literature on the material demand due to the development of the wind turbines within an energy system is fairly limited. (Wilburn 2011) investigated the material demand for onshore wind turbines in the US until 2030 , on the basis that $20 \%$ of the total electricity demand would be fulfilled by wind energy. (Moss et al. 2013) and (Blagoeva et al. 2016) analyzed supply bottlenecks of various low-carbon technologies in the EU. However, the analysis was only conducted for REEs without the consideration of supply risks of other metals. In terms of the deployment of wind turbines specifically in Germany, one of the pioneering works was conducted by (Zimmermann et al. 2013). However, only three different drive trains were considered, which do not cover the entire German market, while the possibility of innovative drive train concepts in the future was excluded. On the contrary, (Viebahn et al. 2014) and (Viebahn et al. 2015) investigated the material demand of more drive train systems as well as novel generator concepts. However, their studies were only focused on the requirements of rare earth elements (REE) in the generator and do not consider other materials that can be found in the entire turbine. Other papers only analyze the material demand of particular components, most notably rotor blades (Mishnaevsky et al. 2017) and generators (Jiang et al. 2018; Lacal-Arántegui 2015). This paper contributes to the existing literature by combining the focuses of the aforementioned publications to present a comprehensive analysis of the metallic raw material requirements for the wind energy deployment by considering the latest technological trends of 8 different wind turbine drive train systems.

The aim of this paper is twofold. Firstly, the future metallic raw material demand for the development of the German wind energy sector is determined. Secondly, any possible supply risk that can arise due to the largescale deployment of wind turbines is identified. In doing so, discuss various wind turbine technologies in terms of their weight and material composition are discussed. Their share in the future technology mix is assessed for several technological roadmaps, accounting for the unsteadiness of future manufacturers' portfolio and policy regulations. In order to realistically estimate the total material requirements, additional demand due to production losses, premature decommissioning of turbines, repairs and component replacements as well as turbine repowerings is considered. The total demand is compared to the reserve levels of each metal and their respective allocations in Germany to identify any possible bottlenecks in the future. 


\section{Data and methodology}

The system boundary of the analysis covers the rotor, nacelle, tower and foundation while connections to the grid, including the voltage lines and transformer substation, are excluded. The analysis is carried out in detail for the components depicted in Figure 2. In addition to the drive-train systems listed in Table 1, two innovative drive-train systems - pseudo direct-drive (PDD) and superconducting direct-drive (SDD - are analyzed as well, as they are expected to be deployed in the near future (see chapter 2.5.3). The technical description of the structure and functionality of PDD and SDD drive-train systems are detailed in (Chaviaropoulos et al. 2015; Penzkofer et al. 2017) and (Jensen et al. 2013; Iker Marino 2017) respectively.

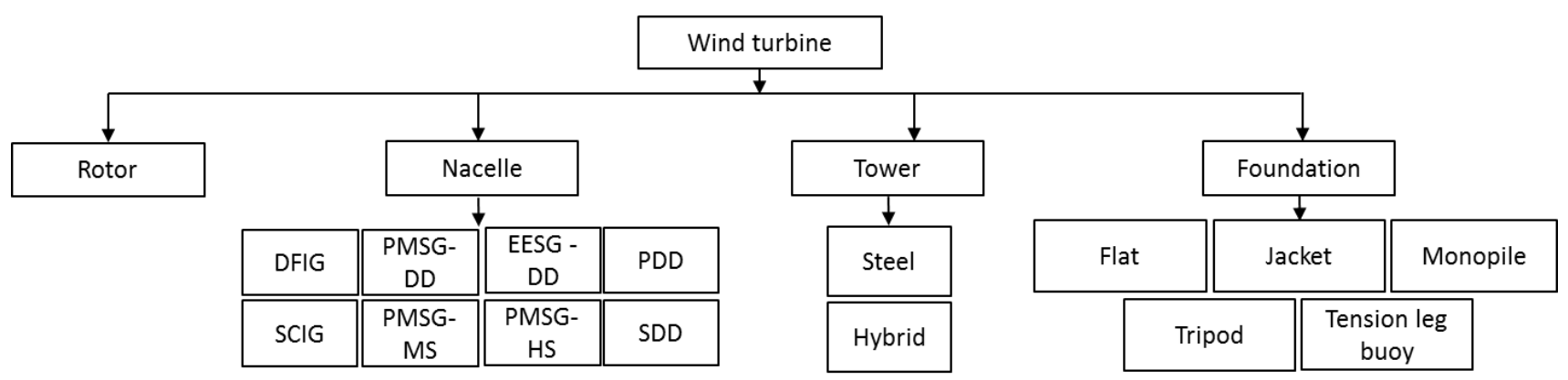

Figure 2: Overview of the turbine components analyzed in this paper

\subsection{Data}

Life-cycle-assessment (LCA) reports and manufacturers' sheets of turbines listed in Table 2 are used to obtain the average material composition of wind turbines. Pre-analysis of the data collected from manufacturers' sheets indicate that present-day wind turbines benefited from technological improvement. As an example, a Vestas V112 model from 2013 has $160 \mathrm{~kg} / \mathrm{MW}$ of PM as opposed $180 \mathrm{~kg} / \mathrm{MW}$ in the V80 model developed before the year 2000 (Eymann et al. 2015). In addition, majority of the turbines present before 2000 are not in production anymore. Therefore, only turbines dating from 2001 onwards are used for the analysis of material composition. The component weights, which are required for the empirical scaling (see section 2.3), are obtained from various manufacturers and literature sources for the turbines listed in Table 3.

Table 2: Overview of the reference turbines used as data basis for the material composition

\begin{tabular}{ccccccc}
\hline $\begin{array}{c}\text { Manufact } \\
\text { urer }\end{array}$ & $\begin{array}{c}\text { Type of Drive } \\
\text { Train System }\end{array}$ & Model & $\begin{array}{c}\text { Nominal } \\
\text { Power }[\mathrm{MW}]\end{array}$ & $\begin{array}{c}\text { Rotor } \\
\text { Diameter [m] }\end{array}$ & $\begin{array}{c}\text { Type of } \\
\text { Tower }\end{array}$ & Source \\
\hline Enercon & EESG-DD & E-82 E4 & 2.3 & 82 & Hybrid & (Eymann et al. 2015) \\
Gamesa & DFIG & G90-2.0 MW & 2.0 & 90 & Steel & (Pereg and Hoz 2013) \\
& & G114-2.0 MW & 2.0 & 114 & Steel & (Carrascal 2014) \\
Vestas & SCIG & V82-1.65 MW & 1.65 & 82 & Steel & (Vestas 2006) \\
& DFIG & V100-2.6 MW & 2.6 & 100 & Steel & (Garrett and Rønde 2013) \\
& PMSG-HS & V90-2.0 MW & 2.0 & 90 & Steel & (Garrett and Rønde 2011) \\
& & V112-3.0 MW & 3.0 & 112 & Steel & (D'Souza et al. 2011) \\
\hline
\end{tabular}


Table 3: Overview of reference turbine models for the empirical upscaling of wind turbines. All data are collected from manufacturers' sheets and various literature sources (Bak and Zahle 2015; Martínez et al. 2009; Bywaters et al. 2004).

\begin{tabular}{|c|c|c|c|c|}
\hline Drive train & Manufacturer & Model & Nominal power [MW] & Rotor diameter [m] \\
\hline \multirow{13}{*}{ DFIG } & \multirow{5}{*}{ Senvion } & MM82 & 2.05 & 82 \\
\hline & & MM92 & 2.05 & 92 \\
\hline & & MM100 & 2.00 & 100 \\
\hline & & $6.2 \mathrm{M} 126$ & 6.15 & 126 \\
\hline & & $6.2 \mathrm{M} 152$ & 6.15 & 152 \\
\hline & \multirow{2}{*}{ Nordex } & AW 70/1500 & 1.50 & 70 \\
\hline & & AW 116/3000 & 3.00 & 116 \\
\hline & \multirow{3}{*}{ Gamesa } & G80-2.0 & 2.00 & 80 \\
\hline & & G90-2.0 & 2.00 & 90 \\
\hline & & G114-2.0 & 2.00 & 114 \\
\hline & \multirow{2}{*}{ Vestas } & V100-2.6 & 2.60 & 100 \\
\hline & & V90-3.0 & 3.00 & 90 \\
\hline & GE Energy & $1.7-100$ & 1.70 & 100 \\
\hline \multirow{7}{*}{ SCIG } & \multirow{4}{*}{ Siemens } & SWT-2.3-93 & 2.30 & 93 \\
\hline & & SWT-2.3-101 & 2.30 & 101 \\
\hline & & SWT-2.3-108 & 2.30 & 108 \\
\hline & & SWT-2.3-120 & 2.30 & 120 \\
\hline & \multirow{2}{*}{ NEG Micon } & NM1500C/64 & 1.50 & 64 \\
\hline & & NM2000/72 & 2.00 & 72 \\
\hline & Nordex & $\mathrm{N}-62$ & 1.30 & 62 \\
\hline \multirow{4}{*}{ PMSG-MS } & Adwen & AD5-135 & 5.00 & 135 \\
\hline & Vestas & V164-8 & 8.00 & 164 \\
\hline & WinWinD & WWD-1-56 & 1.00 & 56 \\
\hline & DTU & $10 \mathrm{MW}-178 \mathrm{~m}$ & 10.00 & 178 \\
\hline
\end{tabular}

\subsection{Material composition of wind turbine components}

The material demand for wind turbines is determined based on the weight percentage in different components. For nacelle, tower and rotor, the arithmetical average of the material composition of turbines listed in table 2 is calculated. The complete compositions of all turbine components that are used in the analysis are listed in tables 4 and 5. Due to the unavailability of data, the composition of the nacelle in PMSG-MS, PMSG-DD, PDD and SDD systems are derived based on following assumptions:

- The material composition of PMSG-MS is assumed to be identical to PMSG-HS, as these drive trains only differ by their gearbox design.

- The copper composition of PMSG-DD is assumed to be similar to a PMSG-HS while the composition of other metals is assumed similar to the EESG-DD since the PM in PMSG-DD only replaces the conventional copper field windings of the rotor, which would otherwise be present in an EESD-DD (Polinder et al. 2006).

- Being direct-drive systems, PDD and SDD have no mechanical gearbox and contain fewer copper windings than the conventional EESG (Chaviaropoulos et al. 2015). Therefore, based on the engineering judgement of the authors, the material breakdown of a PMSG-DD nacelle is used as a proxy for the material composition of PDD and SDD. The difference in the content of PM between PDD and PMSG-DD is presented in Table 6. 
Table 4: Average weight composition [\%] of materials in rotor, nacelle and tower of a wind turbine. The material composition is relative to the respective components and is assumed to be similar for all nacelle sizes according to respective drive train systems. Other materials include polymer and polymer composites such as epoxy and glass fiber, which are not considered in the analysis of this paper.

\begin{tabular}{ccccccccc}
\hline & Rotor & \multicolumn{3}{c}{ Nacelle } & \multicolumn{3}{c}{ Tower } \\
\cline { 2 - 8 } & & DFIG & EESG-DD & $\begin{array}{c}\text { PMSG- } \\
\text { HS/MS }\end{array}$ & $\begin{array}{c}\text { PMSG-DD, } \\
\text { PDD, SDD }\end{array}$ & SCIG & $\begin{array}{c}\text { Steel } \\
\text { tower }\end{array}$ & Hybrid \\
\hline Low alloyed steel & 9.8 & 20.7 & 8.9 & 10.3 & 8.9 & 12.5 & 97.1 & 11.3 \\
High alloyed steel & 9.4 & 36.1 & 29.8 & 39.3 & 29.8 & 41.1 & - & - \\
Cast iron & 25.8 & 35.6 & 52.6 & 41.5 & 52.6 & 35.6 & - & - \\
Aluminium & 0.1 & 1.1 & 0.9 & 0.9 & 0.9 & 1.0 & 1.0 & - \\
Copper & 0.1 & 2.1 & 7.7 & 2.2 & 2.2 & 3.2 & 0.9 & - \\
Electrics/Electronics & - & 0.3 & 0.1 & 0.4 & 0.1 & 0.6 & 1.0 & 1.0 \\
Other materials & 54.8 & 4.1 & 0 & 5.4 & 5.5 & 6.0 & 0 & 87.7 \\
\hline
\end{tabular}

Table 5: Average weight composition [\%] of materials in the foundation of a wind turbine. The material compositions of onshore foundation are determined from the reference turbines in table 2 whereas the data for offshore foundations are obtained from (Briem 2004; Ashuri 2012; Raadal et al. 2014). Other materials include concrete and high-density polyethylene.

\begin{tabular}{|c|c|c|c|c|c|}
\hline \multirow[b]{2}{*}{ Foundation } & Onshore & \multicolumn{4}{|c|}{ Offshore } \\
\hline & Flat & Monopile & Jacket & Tripod & TLB \\
\hline Steel & 4.5 & 100 & 85.8 & 62.7 & 87.5 \\
\hline $\begin{array}{c}\text { Other } \\
\text { materials }\end{array}$ & 95.5 & 0 & 14.2 & 37.3 & 12.5 \\
\hline
\end{tabular}

Steel is further differentiated into raw steel and its alloying metals. High alloyed steel is simplified as stainless steel 18/8 (Eymann et al. 2015) whereas low alloyed steel is simplified as structural steel S355 which represents up to $70 \%$ of the total low alloyed steel amount of a wind turbine (Pereg and Hoz 2013). No specific data on the exact material composition in the electrical and electronic subsystems of a wind turbine are found in the literature. Therefore, the material composition of a generic electronic box is applied in the calculations. The full list of the metal composition of the steel-alloying elements and the electrical and electronic components and their corresponding references are listed in Appendix A.

The requirement of PMs is of special interest due to the presence of REE, particularly neodymium and dysprosium. Although wind turbines become larger as they are built on less suitable area with low wind speed, the nominal power of the turbines might still remain low. This ensures that higher full-load hours can still be reached despite low wind speed, which increases the economic feasibility of such a turbine. In order to precisely estimate the REE demand, their requirement is assessed in relation to the nominal power of the turbines and not the entire weight, which is more relevant for other bulk metals such as copper and steel. Neodymium magnets $(\mathrm{NdFeB})$ are predominantly used in wind turbine generators, with an average composition of $31 \%$ neodymium and $2.3 \%$ dysprosium (Viebahn et al. 2015). The specific amount of the PM in wind turbine is listed in table 6 .

Table 6: Specific weight of permanent magnets in different drive train concepts (Viebahn et al. 2015).

\begin{tabular}{cc}
\hline Drive train & Specific weight $[\mathrm{kg} / \mathrm{MW}]$ \\
\hline PMSG-DD & 650 \\
PMSG-MS & 160 \\
PMSG-HS & 80 \\
PDD & 1350 \\
\hline
\end{tabular}


Besides generators, PMs are also found in certain steel towers. Ladders and platforms are typically welded to the inner surface of a tower. A patented invention by Vestas however, uses the magnetic forces from the PM to attach these on the tower (Oellgaard 2003). This technique limits the use of welding and bolting which may weaken the tower structure, besides saving around 10 tons of steel per tower (Vestas 2012). In the calculations, only the turbine concepts by Vestas will apply this technology, which would lead to an average of $0.02 \%$ of all steel towers to consist of PMs. Similar to the generators, NdFeB magnets are used as they feature strong magnetic attraction compared to other available magnetic materials. Another REE present in a wind turbine is yttrium, which can be found in the superconducting wires of a SDD. These wires are an essential part of the generator as they are capable to conduct approximately 200 times more electrical current than a copper wire of similar dimension (amsc 2013). The type of wire used in a SDD is assumed to be solely based on $\mathrm{MgB}_{2}$ in 2025 , to a combination of $60 \%$ of $\mathrm{REBCO}$ and $40 \%$ of $\mathrm{MgB}_{2}$ in 2050 , as the price of REBCO is considered to drop significantly in the long run (Jensen et al. 2013). Unlike $\mathrm{MgB}_{2}$ which does not contain any REE, superconductor REBCO wires contain $2 \mathrm{~kg} / \mathrm{MW}$ of Yttrium.

Furthermore, in order to account for production losses, correction factors reflecting the material losses bound to the transformation of primary metals are applied to the material demand, as listed in table 7.

Table 7: Correction factor to account for production losses based on (Classen et al. 2009; EAA 2013; Sprecher et al. 2014; EC 2005)

\begin{tabular}{ccc}
\hline Material & Production process & Production efficiency \\
\hline Steel & Hot rolling & 1.05 \\
Cast Iron & Casting & 1.59 \\
Aluminium & Section bar extrusion & 1.32 \\
Copper & Wire drawing & 1.04 \\
PM & Grinding, Slicing & 1.18 \\
\hline
\end{tabular}

\subsection{Upscaling of wind turbine components}

The component weights and the corresponding material demand of future wind turbines will experience significant changes as the turbines are expected to become larger. To account for this, the upscaling method to model the component weights of future wind turbines is applied. Commonly used to estimate properties in relation to the size when no data are available, this method has been previously applied by studies such as (Sieros et al. 2012) and (Caduff et al. 2012) in order to analyze the increase in mass of future turbines. According to these studies, the mass of the turbine components can be explained in relation to the rotor diameter, as shown in equation 1.

$$
\log (M)=\log (a)+\log (D) \cdot b
$$

Where $M$ describes the mass of each component, $a$ is a constant factor, $D$ is the rotor diameter and $b$ is the scaling factor. In the analysis, it is assumed that the future mass of rotors and towers would closely align to the economical optimal. Therefore, regarding rotor and steel towers, constant and scaling factors proposed by (Ashuri 2012) is applied, who optimized the mechanical feasibility and investment costs in determining the dimensions of wind turbine components. Similar to the current situation, hybrid towers are assumed to remain 4 times heavier than steel tower in the future (Eymann et al. 2015). In terms of the nacelle, an empirical upscaling is conducted based on the curve fitting of the data listed in table 3. This is detailed further in Appendix B. The complete coefficients used in this study for the upscaling of the rotor, nacelle and tower are provided in table 8 . 
Table 8: Scaling factors $(b)$ and constants $(a)$ for the upscaling of rotor, nacelle and tower

\begin{tabular}{cccccccccccc}
\hline & Rotor & \multicolumn{1}{c}{ Nacelle } & \multicolumn{3}{c}{ Tower } \\
\cline { 2 - 12 } Type & - & \multirow{2}{*}{ DFIG } & \multirow{2}{*}{ SCIG } & $\begin{array}{c}\text { PMSG- } \\
\text { MS }\end{array}$ & $\begin{array}{c}\text { PMSG- } \\
\text { HS }\end{array}$ & $\begin{array}{c}\text { EESG- } \\
\text { DD }\end{array}$ & $\begin{array}{c}\text { PMSG- } \\
\text { DD }\end{array}$ & PDD & SDD & Steel & Hybrid \\
\hline $\log (a)$ & -3.34 & -2.28 & -1.24 & -2.20 & -2.33 & -3.29 & -3.40 & -2.20 & -1.46 & -4.22 & -3.53 \\
$b$ & 2.56 & 2.13 & 1.59 & 2.13 & 2.17 & 2.70 & 2.70 & 2.13 & 1.75 & 3.22 & 3.22 \\
\hline
\end{tabular}

The foundation mass of future turbines is determined via their respective foundation-to-tower mass ratio. The foundation of onshore turbines is calculated to be 3.5 times heavier than the combined masses of the tower, nacelle and rotor based on the LCAs of Gamesa and Vestas turbines listed in table 3. For offshore turbines, the foundation-to-turbine mass ratios are calculated for existing and planned wind turbines, for which precise data is available from the press releases of wind farm operators (Deutsche Windguard 2017). The ratios of the current offshore turbines are assumed to remain similar until 2035, since most of the planned turbines will be built in areas of similar water depth (see Figure 3 in Chapter 2.6). However, offshore wind farms in Germany are expected to shift to areas with greater water depths beyond 2035. Therefore, it is assumed that the foundation mass for future turbines will increase since structures such as monopile, tripod and jacket has to cover more water depth to mount the turbine to the seabed, which correspondingly requires more materials. Therefore, the increase in mass of the foundation for turbines build beyond 2035 is assumed linear with the increase in average depth at which future turbines will be built on. The water depths of future construction of wind turbines are detailed in chapter 2.6. As for the tension-leg-buoy foundation, its mooring cables are made of high-density polyethylene so that the water depth does not influence the metallic material requirements. The complete mass ratio for the foundation types are given in table 9. The impact of the assumption of linearity between the foundation mass of offshore turbines and water depth are analyzed in a sensitivity analysis in chapter 3.4 .

Table 9: Assumptions regarding the average ratios of foundation mass to turbine mass for different foundation types, compiled from manufacturers' data as well as (Raadal et al. 2014) and (Deutsche Windguard 2017). The average water depth for the period is 2020-2035 is $35 \mathrm{~m}$ whereas the average water depth for 2036-2050 is $45 \mathrm{~m}$.

\begin{tabular}{cc|c|c|c|c|c|c|c}
\hline & \multicolumn{9}{c}{ Offshore } & \multicolumn{3}{c}{ Jacket } & TLB \\
\cline { 2 - 8 } & Flat & \multicolumn{2}{c}{ Monopile } & \multicolumn{2}{c|}{ Tripod } & \multicolumn{3}{c}{} \\
\hline $\begin{array}{c}\text { Year } \\
\begin{array}{c}\text { Foundation- } \\
\text { to-turbine } \\
\text { mass ratio }\end{array}\end{array}$ & - & $2020-2035$ & $2036-2050$ & $2020-2035$ & $2036-2050$ & $2020-2035$ & $2036-2050$ & - \\
\hline
\end{tabular}

\subsection{Material efficiency measures}

Innovative materials, structures and manufacturing processes are currently being intensively investigated in order to increase material efficiency. In this paper, it is assumed that the specific demand for neodymium and dysprosium in the PM to reduce according to table 10 due to improved production processes and substitution of neodymium and dysprosium with less critical metals.

Table 10: Reduction of REE demand in a PM of a generator due to material efficiency measures (Viebahn et al. 2014)

\begin{tabular}{llll}
\hline & 2018 & 2025 & 2050 \\
\hline $\mathrm{Nd}$ & $31 \%$ & $25 \%$ & $20 \%$ \\
$\mathrm{Dy}$ & $2.3 \%$ & $1.8 \%$ & $1.8 \%$ \\
\hline
\end{tabular}


Furthermore, the specific amount of yttrium in the superconducting wires is assumed to reduce from $2 \mathrm{~kg} / \mathrm{MW}$ upon market entry in 2025 to $1.2 \mathrm{~kg} / \mathrm{MW}$ in 2050 due to the more efficient production process (Chaviaropoulos et al. 2015). Besides REE, savings of low alloyed steel are also expected in the tower and foundation. The use of higher grade steels such as S460 or S600 instead of S355 (see Rasmussen (2011) for detailed description of steel grades) in the upper sections of steel towers and the implementation of alternative onshore tower structures, such as the lattice structure (Trabish 2014) could save up to $30 \%$ of steel. Offshore, methods developed in projects such as PISA (Burd et al. 2017) and OFE (Hamm et al. 2015) prove the feasibility of lighter tripod and monopile. The expected savings and their market shares are shown in table 11.

Table 11: Savings of low-alloyed steel and the rate of implementation

\begin{tabular}{|c|c|c|c|c|c|c|c|c|}
\hline \multirow{2}{*}{$\frac{\text { Innovation }}{\text { Year }}$} & \multicolumn{2}{|c|}{ Higher grade steel } & \multicolumn{2}{|c|}{ Alternative structures } & \multicolumn{2}{|c|}{ PISA } & \multicolumn{2}{|c|}{ OFE } \\
\hline & 2020 & 2050 & 2025 & 2050 & 2025 & 2050 & 2030 & 2050 \\
\hline $\begin{array}{l}\text { Savings on total } \\
\text { low-alloyed steel } \\
\text { demand }\end{array}$ & \multicolumn{2}{|c|}{$10 \%$} & \multicolumn{2}{|c|}{$30 \%$} & \multicolumn{2}{|c|}{$25 \%$} & \multicolumn{2}{|c|}{$40 \%$} \\
\hline $\begin{array}{l}\text { Market share of } \\
\text { efficiency measure }\end{array}$ & $\begin{array}{c}40 \% \text { of } \\
\text { steel towers }\end{array}$ & $\begin{array}{c}80 \% \text { of } \\
\text { steel towers }\end{array}$ & $\begin{array}{c}1 \% \text { of steel } \\
\text { towers }\end{array}$ & $\begin{array}{c}25 \% \text { of } \\
\text { steel towers }\end{array}$ & $\begin{array}{c}10 \% \text { of } \\
\text { monopiles }\end{array}$ & $\begin{array}{c}80 \% \text { of } \\
\text { monopiles }\end{array}$ & $\begin{array}{l}5 \% \text { of } \\
\text { tripods }\end{array}$ & $\begin{array}{l}25 \% \text { of } \\
\text { tripods }\end{array}$ \\
\hline
\end{tabular}

\subsection{Technology roadmaps}

In order to calculate the annual material demand until 2050, this paper proposes three technological roadmaps, namely the business-as-usual (BAU), advanced and innovative, which differ in terms of the nominal power of the turbines, rotor diameter and the market share of drive trains. The BAU scenario represents a copperintensive scenario with large market shares of PM-free generators such as DFIG and EESG, whereas the remaining scenarios represent a REE-intensive scenario. The market shares of all scenarios are carefully proposed based on the current market conditions as well as previous projections in the literature, particularly by (Viebahn et al. 2015). The exact market shares of the drive train systems for all scenarios are listed in Appendix C.

\subsubsection{Business-as-usual (BAU)}

The current trend towards larger rotor diameters can be restrained by factors such as legally binding height limitations, urban space competition and infrastructural restrictions bound to the transportation of sizable components. Accordingly, the BAU scenario assumes a stagnation of onshore turbine sizes. Offshore, these challenges are far less relevant. The current logistical difficulty of transportation with high lifting capacities is expected to be overcome as the offshore market becomes more mature. Therefore, the BAU scenario is not applicable to offshore turbines in this paper. Onshore turbines are mostly installed on low wind sites and are associated with small generator designs compared to the size of the rotor (Mathew et al. 2016). The average size of a wind turbine in 2050 is therefore expected not to exceed the current biggest wind turbine adapted to low wind sites, which is the E-141 EP4 model. It features a rotor diameter of $141 \mathrm{~m}$ and a $4.2 \mathrm{MW}$ nominal power. Furthermore, large-scale market entry of innovative drive-train systems is not expected in this scenario as the pressure for innovation is very low. Electrically excited drive-train systems are expected to further dominate the onshore market (Bundesnetzagentur 2017), which means that EESG-DD should remain a major technology in Germany. The strategic leadership of Siemens on the offshore German market and the experience of Gamesa with the onshore DFIG technology in the rest of Europe are assumed to benefit the DFIG turbines in Germany (SGRE 2017). On a different note, Vestas has replaced its PMSG-HS portfolio 
with SCIG in order to limit its dependency towards REEs (Vries 2015). The PMSG-DD remains marginal onshore due to its high cost (Cheng and Zhu 2014). Hence, PMSG-DD and PMSG-HS are assumed to phase out completely by 2020 , replaced by SCIG generators. As a current exclusively offshore concept, the PMSGMS is not expected to enter the onshore market before 2030. Featuring a better energy yield than the DFIG and SCIG, at a similar manufacturing cost, it is expected to gradually take over market shares from them.

\subsubsection{Advanced}

The barriers addressed in the BAU scenarios are assumed resolved in the advanced scenario through increasing experience over time. As a result, the sizes of wind turbines are expected to grow substantially in this scenario. The technical feasibility of a $20 \mathrm{MW}$ offshore wind turbine with an optimized $286 \mathrm{~m}$ rotor diameter has been previously proven viable by (Ashuri 2012). In order to avoid technically, logistically and economically challenging turbine masses, the advanced scenario assumes a technology shift towards lighter drive-train types. Therefore, EESG-DD is expected to lose onshore market shares while the much lighter direct-drive system, the PMSG-DD and PMSG-MS, should largely benefit from this niche. It is possible that Vestas returns to manufacturing PMSG-HS, thus providing an additional light synchronous generator to the market. Due to its relatively low efficiency though, PMSG-HS should, however, remain sparsely implemented. As for the DFIG, being among the lightest available technologies, and already manufactured by several suppliers, it is assumed to dominate the wind energy market in the future. Only three types of drive train systems are planned for offshore installation from 2017 to 2019, namely PMSG-DD, PMSG-MS and DFIG (Deutsche Windguard 2017). The reliability of the technologies implemented at sea is a crucial parameter as any maintenance operation requires special equipment and is subjected to accessibility restrictions tied to weather condition. The above-mentioned turbines, being the systems with the lowest failure rates (Carroll et al. 2016), are expected to remain the solely deployed drive train systems offshore up to 2050. Owing to its higher efficiency and reliability, PMSG-DD is assumed to dominate the market, followed by the PMSG-MS and DFIG.

\subsubsection{Innovative}

The innovative roadmap can be understood as similar to the advanced scenario with the assumption of a market entry of the innovative PDD and SDD drive-train systems. The SDD has been the focus of the research in the wind energy industry for years with already planned wind turbine installations. In terms of the PDDgenerators, the InnWind project (Stehouwer and van Jan Zinderen 2016) demonstrates that a lower LCOE can be achieved compared to the SDD-generators. However, it is too early to conclude that the former technology might be preferred by turbine manufacturers due to the uncertainties of the superconductors' prices. Hence, similar market shares for both concepts are assumed, with a market entry scheduled in 2025 . Onshore, these generators are expected to take over the market shares of heavier drive train systems, such as PMSG-DD and EESG-DD. However, DFIG is expected to remain the market leader because it benefits from long years' experience, manufacturing without any rare earth elements and is still lighter than the superconducting design. Offshore, DFIG and PMSG-MS are expected to lose some shares to the benefit of the PDD and its more reliable magnetic gearbox. 


\subsection{Evolution of support designs}

For the market shares of the steel and hybrid concrete towers, the projections proposed by (Zimmermann et al. 2013) is assumed. In terms of the foundation, only the conventional large concrete slab foundation is considered for onshore turbines. Offshore, wind farms are geographically pooled into clusters, for which one or several grid connection points are planned. Based on the average water depth of these clusters and the type of foundation used in the nearby existing wind farms, the foundation types for future wind farms are projected. Clusters, foundations and water depths used to determine the market shares of foundations in the North Sea are illustrated in Figure 3. The planned grid connection points, their respective maximum capacities and the clusters that will be connected to them up to 2035 are provided by (Deutsche Windguard 2017).

Until 2030, grid connections and the corresponding clusters are mainly located in areas up to 40m water depth. Monopiles are traditionally implemented for these depths and are therefore expected to remain as the market leader in Germany. From 2030 onwards, grid connections in the North Sea are dedicated to the clusters 9, 11, 12 and 13 located in Zone 2, with average water depths of 40-50m. The tripods are well suited to this environment, and therefore are expected to have the largest market share by 2035 . This would be followed by the monopiles which would still be implemented for the shallower areas. Currently, still in the development phase, the floating foundations would further gain importance as they become more mature and cost-effective and are assumed to enter the market in 2035. The jacket, which is almost solely used in the Baltic Sea, is expected to regain market shares by being implemented in the available zone with $40-50 \mathrm{~m}$ water depth. Beyond 2040, the construction sites are expected to gradually shift towards zones 3 and 4 of the North Sea, with water depths up to $60 \mathrm{~m}$. Therefore, tripods are assumed to lose shares to the benefit of the TLB foundations (Myhr 2016). Monopiles remain a conventional mature technology which is expected to be used for the lower depth ranges. Market shares of the offshore foundation types are shown in detail in Appendix D. 


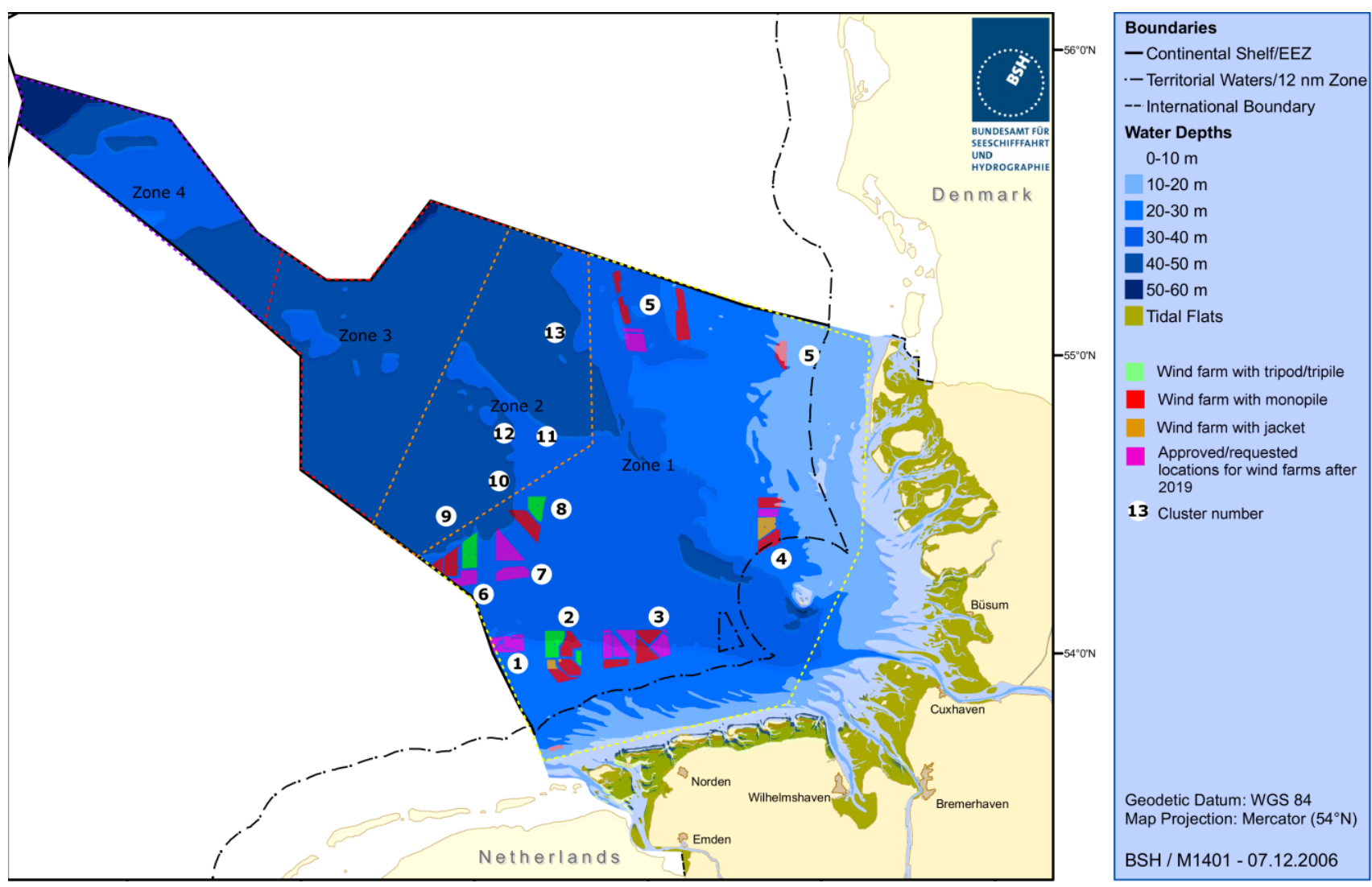

Figure 3: Geographical location of existing and requested wind farms in the German Exclusive Economic Zone of the North Sea, represented with foundation types, water depths and clusters (Deutsche Windguard 2017; BSH 2017, 2006, 2013). The figure is expanded with manufacturers' data of wind farms

\subsection{Installed capacity}

In order to determine the annual material demand, the specific material demand and their respective market shares are multiplied with the projected installed capacity of wind turbines. In this paper, three energy scenarios for Germany, which was published from 2014 onwards are selected, namely GROKO (Nitsch 2014), IEE (Fraunhofer IWES et al. 2015) and REMod (Henning and Palzer 2015). These scenarios propose a target system that reduces the $\mathrm{CO}_{2}$ emission by at least $85 \%$ in comparison to the emission in 1990, which is in accordance with the environmental goals set by the German government. All scenarios consider the electricity, heat and transportation sectors in their analysis. The main reason for the difference in the projections is the different assumptions made by the authors in forecasting the development of the total energy demand and the implementation of energy efficiency measures. The net installed capacity of onshore and offshore wind turbines in 2050 proposed by these reports are presented in figure 4 .

While the annual installed capacity of wind turbines from the REMod scenario is available, the remaining scenarios only provide the cumulative capacity either for the target year or for selected years. For these scenarios, the annual installed capacities are extrapolated based on current installed capacity. Furthermore, the additional demand needed to compensate planned and premature decommissioning of turbines is also considered. There are several reasons for dismantling a wind turbine before the end of its theoretical lifespan such as worn out material, spare parts no longer being produced by suppliers or it is simply more profitable to replace old turbines with new ones. The Weibull distribution according to (Zimmermann et al. 2013) is applied in order to model a more accurate lifespan of wind turbines and to determine the decommissioned material demand. 


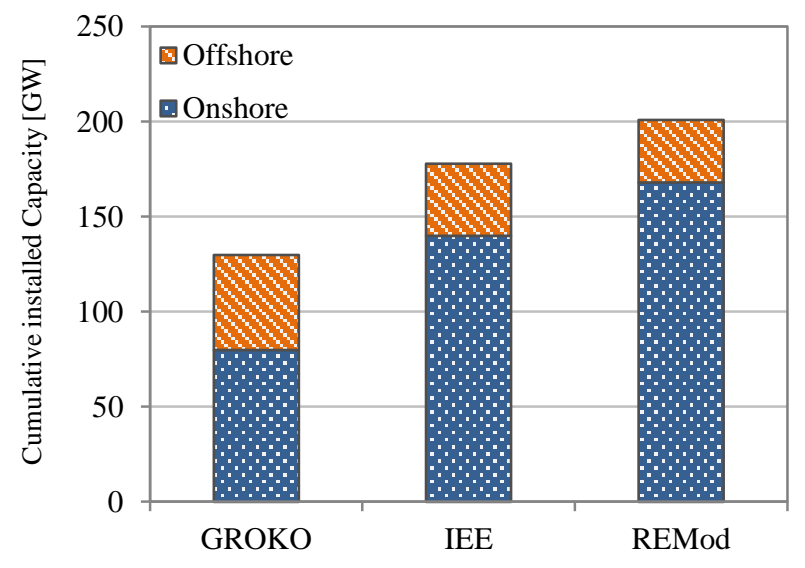

Figure 4: Cumulative installed capacity of on- and offshore wind turbines in Germany in 2050 as proposed by different energy scenarios.

\subsection{Maintenance and repair}

During the lifespan of a wind turbine, most components experience failures which require material-consuming maintenance operations. However, component failures do not necessarily mean replacements: materialconsuming repairs should also be taken into account. Due to the complexity and the large variety of the wind turbine components, only the components with the most frequent failure rates, as presented by (Sheng 2013) and (Carroll et al. 2016), are considered in the material requirement calculation, namely the pitch, gearbox and yaw. Additionally, the generator failures are also included due to the presence of REEs. The failure rates per year and per turbine of the selected components, as listed in table 12, are adapted based on (Carroll et al. 2016) and (Carroll et al. 2017). Technical improvements of turbine components are continuously being sought. On the one hand, more reliable generators might be achieved through experience or structural modifications, such as the development of brushless DFIG that is less prone to failures than the conventional DFIG (Polinder et al. 2013). On the other hand, more sophisticated and complex components could also be developed in order to improve the yield of the turbine, which might mean higher failure rates. Considering the uncertain future evolution of components reliability, constant failure rates per turbine per year are considered for the material requirements calculation up to 2050. Due to the lack of real data and the relatively small market share, the failure rates of the PDD and SDD drive train systems are not considered. The implications of the omission of failure rates for PDD and SDD on the results are discussed in chapter 3.4.

Table 12: Annual failure rates per turbine for pitch, yaw, gearbox and generator for different drive train systems

\begin{tabular}{ccccccccccc}
\hline & Pitch & Yaw & \multicolumn{3}{c}{ Gearbox } & \multicolumn{6}{c}{ Generator } \\
\cline { 2 - 12 } & - & - & $\begin{array}{c}\text { Multiple- } \\
\text { stage }\end{array}$ & $\begin{array}{c}\text { Single- } \\
\text { stage }\end{array}$ & DFIG & $\begin{array}{c}\text { PMSG- } \\
\text { HS }\end{array}$ & $\begin{array}{c}\text { PMSG- } \\
\text { DD }\end{array}$ & $\begin{array}{c}\text { PMSG- } \\
\text { MS }\end{array}$ & $\begin{array}{c}\text { EESG- } \\
\text { DD }\end{array}$ & SCIG \\
\hline $\begin{array}{c}\text { Major } \\
\text { replacement }\end{array}$ & 0.001 & 0.001 & 0.059 & 0.042 & 0.109 & 0.007 & 0.009 & 0.008 & 0.109 & 0.109 \\
Major repair & 0.179 & 0.006 & 0.042 & 0.03 & 0.356 & 0.024 & 0.03 & 0.026 & 0.356 & 0.356 \\
Minor repair & 0.824 & 0.162 & 0.432 & 0.305 & 0.538 & 0.437 & 0.546 & 0.473 & 0.538 & 0.538 \\
\hline
\end{tabular}

Turbines that undergo maintenance include those which have been repowered in each year, as failures can occur from the very first year of installation. Additional material demand from maintenance is not considered 
on the decommissioning year of turbines. In order to calculate the future demand for maintenance operation precisely, each component listed in table 12 are upscaled separately according to the methodology presented in chapter 2.3. For each minor repair, $10 \%$ of the material is replaced whereas a major repair requires $20 \%$ of the additional material. The upscaling parameters and the material composition of the related components are listed in Appendix E.

\subsection{End-of-life recycling}

Using the recycling rates of selected materials as listed in table 13, the annual amount of secondary metal flow is calculated. To the best knowledge of the authors, the material recycling in the wind turbine industry is not a closed loop, i.e. the recycled material is not completely used in order to make new turbines, instead deployed in other industries. This is partly owed to the fact that the industry is currently gradually maturing and the infrastructure and facility to easily recycle a turbine is currently not sufficiently available (Ortegon et al. 2013). Based on the identification of these secondary material flows, the theoretical potential of a closed-loop recycling can be assessed to avoid supply bottlenecks in chapter 3.2.

Table 13: Recycling rate of selected material in a wind turbine (Andersen et al. 2014)

\begin{tabular}{cc}
\hline Material & Recycling rate [\%] \\
\hline High alloyed steel & 98 \\
Low alloyed steel & 95 \\
Cast iron & 95 \\
Aluminum & 95 \\
Copper & 98 \\
PCB & 50 \\
Magnets & 98 \\
\hline
\end{tabular}

\subsection{Criticality assessment}

Since an economical and secure supply of raw materials is an important factor to ensure a large-scale deployment of a technology over time, the need to designate the criticality of material usage has been gaining importance lately (Graedel and Reck 2016). In this paper, the supply risk in terms of the geological availability is selected as the most suitable criteria in order to quantitatively assess the material demand resulting from the deployment of wind turbines. Therefore, this paper adopts the approach proposed by (Viebahn et al. 2015) and (Habib and Wenzel 2016). The former, known as static approach, uses the principle of fair allocation in order to define material consumption limits in Germany. This approach defines the amount of material from the world's static reserve that is allowed to be used in Germany to be 1\%, which is chosen based on the proportion of German population with respect to the global population. In addition, only $10 \%$ of this amount is allocated for renewable energy technologies (Viebahn et al. 2015). A total metal demand above this limit considered critical. Meanwhile, in the second approach, the total material demand is compared to the reserve-base. This is known as the dynamic approach. The reserve base additionally considers the currently idle sub-economic reserves, which could be economically attractive and operated in the future due to the improvements in mining techniques and growing pressure on some metals. For the comparison of demand and reserves, correction factors are considered to include metal losses from mining to metal production. Moreover, the secondary metal share from scrap in the metal production is not included as only the primary demand that are required to be mined are compared with the reserve levels. These correction factors are provided in Appendix F. The static reserves are obtained from the (USGS 2017) whereas the reserve-base are obtained mainly from (USGS 2009). The full reserve levels are also provided in Appendix F. 


\section{Results and discussions}

\subsection{Primary material requirement}

Results show that steel is the most intensively required material for the deployment of wind turbines, followed by copper and alloying elements such as chromium, manganese and nickel. Full results are provided in Appendix G. Figure 5 shows the cumulative material demand from 2018 until 2050 for selected metals. Generally, the demand is strongly dependent on the total installed wind turbine capacities proposed by the energy scenarios. For instance, the REMod scenario, which has the highest total installed capacity of wind turbines, has the highest demand compared to GROKO and IEE for each respective development scenario. Besides that, the BAU-scenarios generally require the least material amount among all investigated scenario.
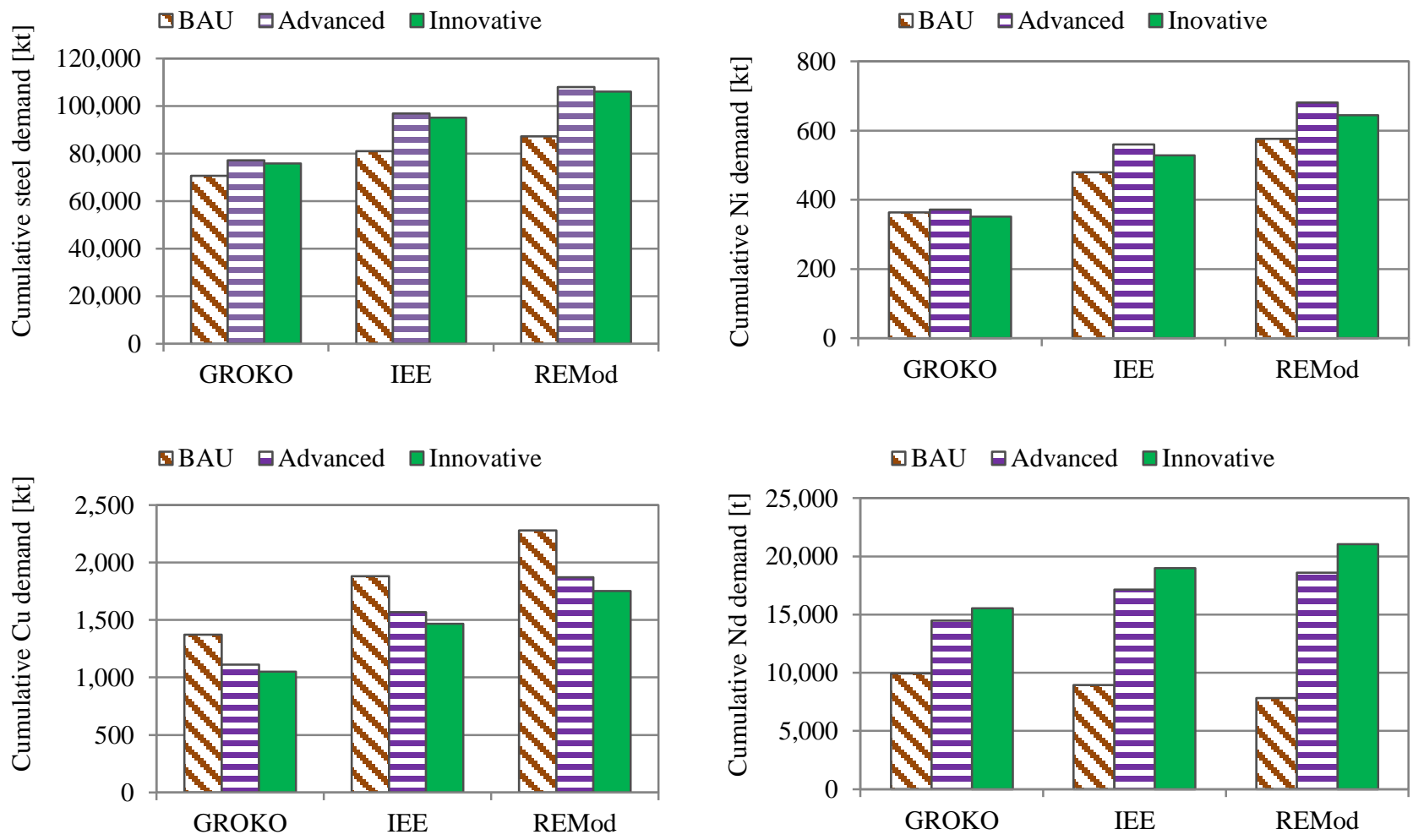

Figure 5: Cumulative demand of selected metals for on- and offshore wind turbines from 2018 until 2050

However, there are two exceptions to these general trends observed in the results. Firstly, the demand for neodymium is the highest in the GROKO-BAU scenario, followed by the IEE-BAU and REMod-BAU scenario. Although the total installed capacity is the lowest, the GROKO scenario has the highest installed capacity of offshore turbines, where the deployment of turbines with PM is the most intensive. However, this effect is not seen in the advanced and innovative scenario. This can be explained by the shift in the market towards drive train systems with PMs in the advanced and innovative scenarios. Since turbines with PMs would also be widely installed on shore in both scenarios, the demand for REE increases with respect with the total installed capacity. Due to a higher concentration of REE in PDD drive trains systems, the highest REE demand is observed in the innovative scenario.

Secondly, the copper requirement in the BAU-scenario is significantly higher relative to the other scenarios. This is due to the fact that the BAU-scenario is characterized by the intensive use of EESG-DD drive train, 
which is bound to a nacelle containing at least twice more copper than other systems in the form of generator windings. This leads to an overall high demand of copper in the BAU scenario. Besides that, the innovative scenario requires slightly less steel than the advanced scenario since the innovative drive train systems are lighter than their counterparts, which also correspondingly leads to lighter towers and turbine structures. The trend of nickel requirement is observed to be very similar to steel due to the dependency of nickel as an alloying element. Similar trends are also observed for manganese and chromium.

Figure 6 shows the annual demand of copper and neodymium from 2018 until 2050 for the REMod scenario. The observed average annual increase is contributed by two main reasons. Firstly, the installed capacity of the wind turbines increases each year, which calls for more primary material demand as well as demand due to maintenance, repair and component changes. Secondly, as the turbines grow larger, the specific material usage in a turbine increases due to the upscaling effect. From the intensity-of-material-usage point of view, bigger turbines can, therefore, seem unfavorable as it requires greater material demand. However, larger turbines can reduce the cost of manufacturing due to learning effect, requires less specific area of installation $\left(\mathrm{MW} / \mathrm{m}^{2}\right)$ and improve the sustainability of the produced electricity, such as by reducing the energy pay-back time and greenhouse gases during the manufacturing process (Caduff et al. 2012). Therefore, manufacturers would most probably continue efforts in producing larger turbines despite the increase in the material intensity. The effect of the increasing size of the turbines is discussed further in the next section.
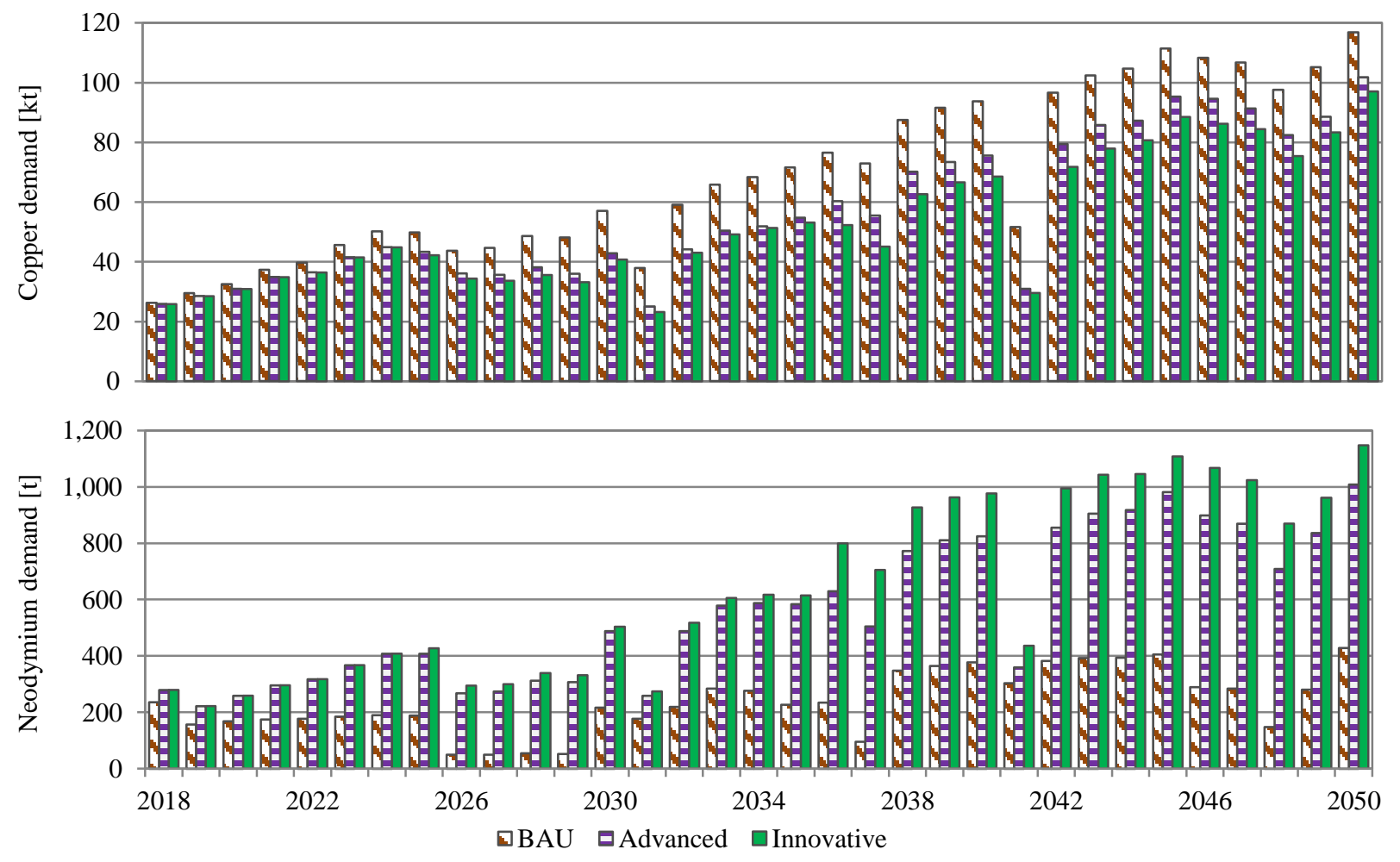

Figure 6: Annual demand of copper (top) and neodymium (bottom) according to the REMod scenario (Henning and Palzer 2015). The sudden drop in demand observed in 2031 and 2041 is owed to the model results provided in the REMod scenario, in which the optimization model does not install any wind turbines in those years. The material demand observed in 2031 and 2041 is a result of maintenance and component exchanges.

The material demand can be broken down to three components, as shown exemplarily for chromium in figure 7. An average of one-fifth of the total cumulative material demand comes from component repairs and exchanges, specifically in the pitch, yaw, gearbox and generator, with the BAU-scenario having a larger share 
than the remaining scenarios. This is valid for almost all investigated metals except for the REEs as they are deployed more in the advanced and innovative scenarios. Figure 7 also shows the advantage of drive-train systems with higher reliability, such as PMSG which are deployed intensively in the advanced and innovative scenarios, as they require less material for repairs and component exchanges. This could prove as an important argument for investors to decide for such turbines despite the existence of REE as these turbines are more economical due to lesser operational costs and maintenance efforts during the entire lifespan.

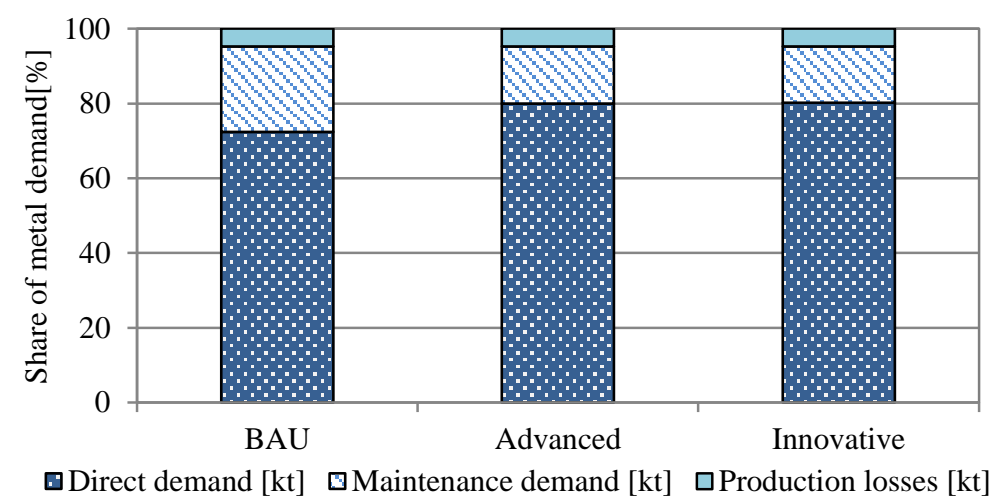

Figure 7: Percentage of material demand from direct demand, maintenance and repair as well as production losses

\subsection{Supply availability}

In this section, the cumulative material demand to their respective reserves is compared. The ranges of the supply risk over all scenarios are displayed in figure 8. The requirements of 7 particular metals exceed the allocated budget of static geological reserves, in either all or some of the scenarios. The REMod-Advanced scenario, based on the assumption of significantly larger turbines in the future, presents the highest risk among these metals, with the requirements for nickel reaching more than 10 times of the allocated budget. In the dynamic approach, the supply needs of chromium, tin, manganese and antimony lie beneath the allocated budget, with the demand of nickel, copper and dysprosium still remains higher than the maximum allocation limit.

Despite posing the greatest risk, it should be mentioned that nickel is predominantly used as an alloying element and does not contribute directly to the functionality of a wind turbine. Therefore, the demand for nickel can be reduced by decreasing the demand for steel. This can be achieved by increasing the share of concrete towers and the share of steel lattice towers as well as increasing the deployment of floating, jacket and tripod foundations in offshore turbines, as these measures are able to reduce the steel demand drastically. Substituting the currently used stainless steel to ferrite grade stainless steel, which requires significantly lesser nickel, is also possible when fabricated and applied accordingly. On the contrary, the high demand of copper and dysprosium is more alarming since these metals are fundamental to the functionality of a wind turbine, with one being the alternative for the other, in terms of generators with copper windings or with PM. The supply risk of copper is of particular interest as it has not been identified before in the literature within the context of the deployment of wind turbines in Germany, since the research was only focused on the REE (Viebahn et al. 2015) or the scope of considered drive-train systems were very limited (Zimmermann et al. 2013). 


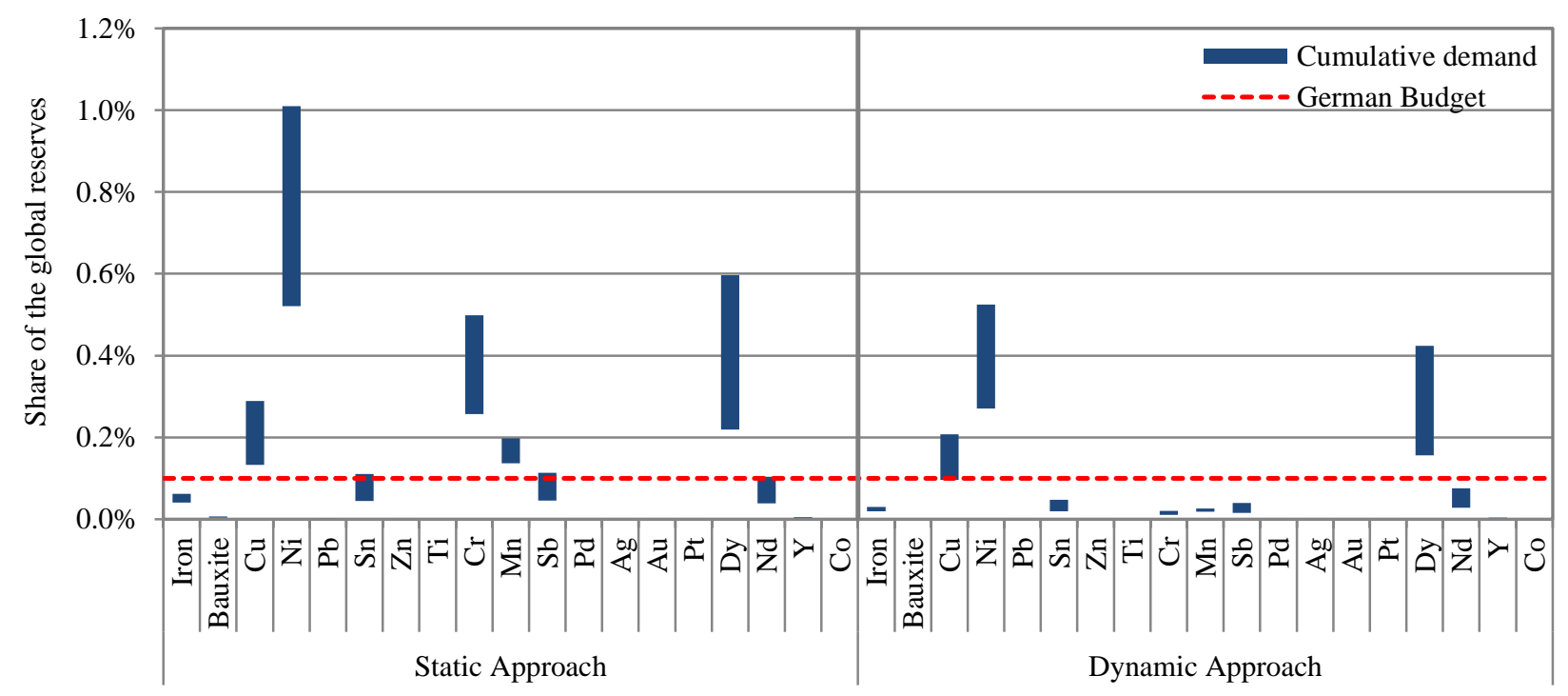

Figure 8: Supply risks for metals according to the static and dynamic approach. The REMod-Bau and GROKOInnovative scenarios provide the top and bottom of the demand range of copper respectively. The REMod-Innovative and REMod-BAU provide the top and bottom of the demand range of dysprosium and neodymium respectively. For the remaining metals, the top of the demand range is provided by the REMod-Advanced scenario whereas the bottom of the range comes from the GROKO-BAU scenario.

By exceeding the allocated limit, the wind energy industry has to compete with other sectors in order to secure the amount of copper and dysprosium that is fairly allocated for Germany. It is worth considering that the maximum allocation limit can be higher than $0.1 \%$ in the future if more metals are reallocated to the electricity generation sector. However, this seems very unlikely as other sectors are also expected to grow in the future. For instance, almost $45 \%$ of current copper demand is used in making power transmission lines while $8 \%$ is used in the automobile sector (IWCC and ICA 2017). In terms of the NdFeB-magnet that contains dysprosium, almost half of the total demand goes into making electric motors (Glöser-Chahoud et al. 2016). The metal demand in these sectors will definitely rise in the future since increasing the share of renewables in the German energy system will consequently require power grid expansion (Rippel et al. 2018). Besides that, the German government is also making efforts in proposing policies in order to facilitate the expansion of electric vehicles in the future (BMWi 2018b). Therefore, it is assumed that the allocation limit of $0.1 \%$ will not increase and still be valid in the future.

\subsection{Potential of material recycling}

In this section, the material recycling potential of wind turbines and its ability to mitigate supply risks is analyzed, particularly for copper and dysprosium. Figure 9 exemplarily shows the annual recyclable copper demand and its potential in reducing the primary copper demand in the GROKO-BAU scenario. Almost $430 \mathrm{kt}$ of copper would be available to be recycled from 2018 until 2050 according to this scenario, thus reducing the cumulative requirements from $1050 \mathrm{kt}$ to $620 \mathrm{kt}$. In the REMod-Innovative scenario, which has the highest copper requirements, $1200 \mathrm{kt}$ of copper can be recycled, massively reducing the cumulative requirements from $2200 \mathrm{kt}$ to only $1000 \mathrm{kt}$. Overall, approximately 45 to $60 \%$ of copper demand between 2018 and 2050 across all scenarios can be recycled. On the contrary, the recycling potential of dysprosium is much lower, as only 20 to $32 \%$ of the total demand would be available for recycling between 2018 and 2050 . This is due to the fact that the market share of drive trains with PM is currently low, with the expected large- 
scale offshore expansion materializing in the future. The in-use stocks are expected to grow and would be available for recycling beyond 2050 .

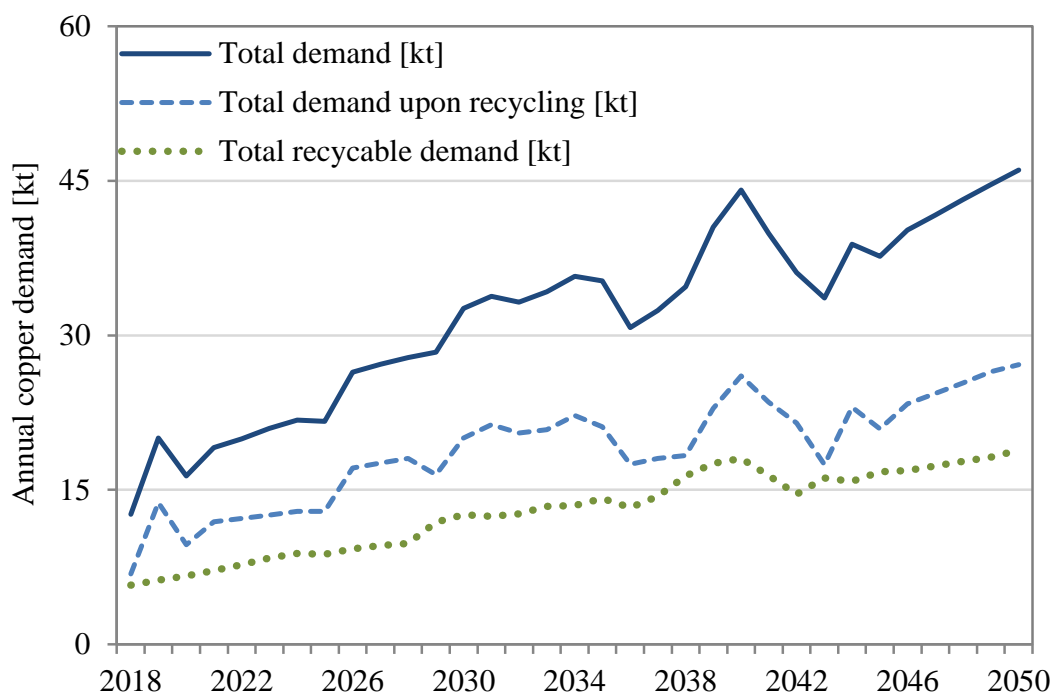

Figure 9: Effect of a closed-loop copper recycling in the GROKO-BAU scenario. The difference between the total demand and the total recyclable demand gives the total demand upon recycling.

As shown in figure 10, the remaining dysprosium demand upon recycling still exceeds the maximum allocation limit. The risk of copper on the other hand, is partly mitigated according to the static approach and almost completely overcome in the dynamic approach. This result indicates that an alternative scenario beyond the definitions in this paper may exists which might have a lower supply risk for the demand of dysprosium, as copper still has the ability to increase its demand up to the maximum allocation limit. Market shares of generators such as DFIG and EESG can be theoretically increased, which will consequently lower the demand for dysprosium. However, this might come at a price, since these generators are less reliable than their counterparts with PMs. Nonetheless, one effective way of investigating this would be to incorporate the information regarding the material use and availability in energy system optimization models. This enables energy pathways that are not only cost-minimal but also have a minimum supply risk of raw material to be established.

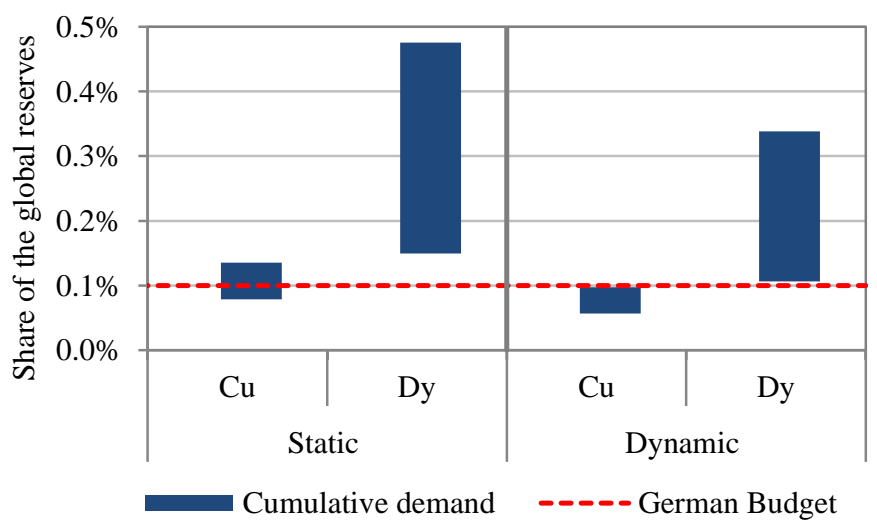

Figure 10: Range of supply risks of copper and dysprosium upon considering a closed-loop recycling based on all analyzed scenarios 
Although recycling does not completely remove the supply risks of dysprosium, it does reduce the supply risk significantly. It appears to be a key strategy in decreasing the overall primary material demand and improving the sustainability of a wind turbine. Although there are already established markets for scrap metals, turbine recycling is still at an early stage of development, in particular, the reprocessing of rare earth elements is still highly limited by process costs and output quality (Binnemans et al. 2013; Royen and Fortkamp 2016). Furthermore, such a closed-loop recycling, in reality, may require more energy and more material due to production losses and quality degradation of material (Adibi et al. 2017). These aspects should be assessed in detail in order to prepare the industry to utilize the high material recovery potential that wind turbines have to offer in the future, which will, in turn, benefit the wind energy sector by easing any possible supply risks.

\subsection{Sensitivity analysis of results}

Sensitivity analyses are conducted to investigate the impacts of several assumptions on the results in this paper. Firstly, the assumption of the linearity of the foundation mass with the average water depth is tested. In the sensitivity analysis, the linearity is neglected, as the current foundation-to-turbine mass ratios are assumed to remain similar until 2050. In doing so, the steel demand in the GROKO-BAU scenario reduces by $7 \%$. The copper demand, which is an alloying element in the low-alloy steel, reduces by $3 \%$. Since the corresponding bottleneck risk remains unchanged in the sensitivity analysis, it can be concluded that the assumption of linearity between foundation mass and the water depth does not significantly affect the final results.

In the second analysis, the impact of neglecting the failure rates of PDD and SDD in the innovative scenario due to data unavailability is tested. Since one of the main advantages of both concepts is improved reliability (Chaviaropoulos et al. 2015), the failure rates of the PMSG-HS generators are therefore assumed for PDD and SDD. This results in a $0.6 \%$ increase of chromium and copper demand. Correspondingly, the share of material demand due to maintenance in the innovative scenario in Figure 7 slightly increases by $0.4 \%$. The bottleneck risks of all metals remain unchanged.

Last but not least, the sensitivity of the allocation limits is discussed. Wind turbines might face competitions from other renewable energy technologies in securing raw materials, particularly from photovoltaics (PV) that is also expected to undergo massive expansion. However, the active materials in both technologies vary significantly. For instance, while copper and REEs are fundamental to the functionality of wind turbines, metals such as silicon, indium and cadmium are fundamental for the functionality of PV modules. Therefore, less competition between both technologies can be expected in the future. Nonetheless, PV systems do require copper for electrical wirings. Results in Figure 10 show that the allocation for copper can theoretically be reduced by $20 \%$ in the static approach and by $40 \%$ in the dynamic approach for the development scenarios that provide the least bottleneck risks. This copper demand can then be reallocated to other renewable energy technologies.

\subsection{Further potential of reducing material demand}

Although only two materials are proven to be critical in the results, the need to intensify research efforts and to further reduce the total material demand should not be undermined to continue increasing the holistic sustainability of the electricity production from wind turbines. Improving manufacturing techniques will clearly help in reducing the production losses, which currently amounts to an average 5\% of the total material demand. Another strategy is to make efforts in improving the reliability of wind turbine components, which would reduce the additional demand due to repair and component exchanges. Improved reliability might also 
indirectly lead to the reduction of REE demand. Turbines with PM benefit, among others, from their higher reliability and lesser maintenance costs especially for deep-sea offshore turbines. By improving the reliability of electrically-excited turbines, the requirements for turbines with PMs can be suppressed, thus reducing the demand for REE. This however might incidentally lead to the increase of copper demand, a possible effect which has to be considered and analyzed in detail.

Besides that, improving material efficiency can contribute to reducing the material demand in particular components. For example, an improved design or even lowering the working temperature of a turbine can reduce the amount of REE in a PM (Yang et al. 2017). Apart from that, material substitution plays another important role in reducing potential supply risks. Measures such as substituting dysprosium with cerium and cobalt while reducing the amount of neodymium in $\mathrm{NdFeB}$ magnets (Pathak et al. 2015) or even completely replacing the common $\mathrm{NdFeB}$ magnets with ferrite magnets (Campos et al. 2018) can contribute in significantly reducing the REE demand. However, these measures are still in a research phase and require more advancement before market entry.

Raw material requirements have been estimated under the assumption that the general design and material composition of wind turbines will not radically transform in the next decades. This could however change in the future, with possibly groundbreaking designs being investigated, such as the bladeless design developed by Vortey Bladeless, helium-filled floating wind turbines tested by the MIT startup Altaeros Energies or even more sustainable horizontal-axis wind turbines (Aso and Cheung 2015). Currently, it is too early to assess the potential of these technologies. However, if more resources are invested in the research of these alternative concepts, they can clearly rival the conventional three-blade wind turbines in the future and reduce the material use in the wind energy sector.

\section{Conclusions and further works}

In this paper, the total material demand due to the deployment of wind turbines in Germany as proposed by recent studies on the future energy system is analyzed. In doing so, different market development scenarios of wind turbines were considered, while taking innovative designs and material efficiency measures into account. The additional demand due to repairs and component exchanges was modeled for components with the highest failure rates. Lastly, the total material demand was compared to their respective reserves in order to identify any supply risks, with the potential of recycling in overcoming the risks being investigated as well.

Based on the results, copper and dysprosium are identified as the most critical metals particularly due to the high demand with respect to the current availability and lack of feasible and economic measures to mitigate the possible supply risks in the future. Under current market conditions, copper and dysprosium are alternatives for each other. On one hand, the BAU-scenario, which assumes that the dimensions of wind turbines remain fairy the same as the current state, faces a supply bottleneck of copper, as this scenario extensively deploys turbines with electrically-excited-generators with copper windings. On the other hand, the advanced and innovative scenarios, which move towards much sustainable larger turbines, face the possibility of supply risks for dysprosium. While material recycling can facilitate in reducing the supply risks, it does not completely mitigate them. However, if the reserve level of copper increases in the future, then the additional availability can ease the possible supply bottlenecks that might be faced by copper.

Since the supply risks of copper are substantially lower than that of dysprosium, it can be concluded that smaller wind turbines with electrically-excited generators are, from the perspective of material availability, a better option in the future. However, significantly larger areas are required in order to install such wind 
turbines to fulfill the future electricity generation requirements, which would lead to strong competition with other sectors, particularly agriculture. Although larger innovative turbines may face supply bottlenecks in the future, their production proves to be more sustainable, cost-effective and requires less specific area of installation. Therefore, a strategic compromise has to be found on how to apply the wide range of turbines effectively both on- and offshore, in order to sustainably contributing to the energy transformation process.

Furthermore, measures such as improving production techniques, increasing the reliability of turbine components, using lightweight support structures as well as substituting critical materials with less critical ones will certainly help in reducing supply risks. Besides that, efforts in optimizing the recycling process of wind turbines should also be undertaken in advance to prepare for the large-scale decommissioning of turbines in the coming years. It should be mentioned that the future deployment of wind turbines proposed by the energy scenario is required in order to meet the national environmental goals. With the current status of wind turbines, these goals cannot be met sustainably in Germany and require significant disruptive changes in the design, manufacturing and the implementation of wind turbines.

\section{Acknowledgement}

This work was supported by the Reiner Lemoine Stiftung. 


\section{Publication bibliography}

Abrahamsen, Asger B. (2016): New direct drive technologies of INNWIND.EU. Superconducting vs. Pseudo Direct Drive. Wind Energy Denmark. Odensee, Denmark.

Adibi, N.; Lafhaj, Z.; Yehya, M.; Payet, J. (2017): Global Resource Indicator for life cycle impact assessment. Applied in wind turbine case study. In Journal of Cleaner Production 165, pp. 1517-1528. DOI: 10.1016/j.jclepro.2017.07.226.

amsc (2013): Second generation HTS wire for high-current cable and power-dense coil applications. American Superconductors. Available online at http://www.amsc.com/solutionsproducts/hts_wire.html, checked on 12.05.17.

Andersen, Per Dannemand; Bonou, Alexandra; beauson, Justine; Bronsted, Povl (2014): Recycling of wind turbines. DTU International Energy Report 2014: Wind energy - drivers and barriers for higher shares of wind in the global power generation mix. Edited by H. Hvidtfeldt Larsen, \& L. Sønderberg Petersen. Technical University of Denmark (DTU).

Ashuri, Turaj (2012): Beyond classical upscaling. Integrated aeroservoelastic design and optimization of large offshore wind turbines. Doctoral Thesis.

Aso, Raymond; Cheung, Wai Ming (2015): Towards greener horizontal-axis wind turbines. Analysis of carbon emissions, energy and costs at the early design stage. In Journal of Cleaner Production 87, pp. 263-274. DOI: 10.1016/j.jclepro.2014.10.020.

Bak, C.; Zahle, F. (2015): The DTU 10MW Reference Wind Turbine. Science Meets Industry. DTU Wind Energy. Bergen. Available online at http://www.norcowe.no/doc/konferanser/2015/SMI\%20Bergen/Presentasjoner/The\%20DTU\%2010MW \%20Reference\%20Wind\%20Turbine\%20-\%20Bak\%20-\%20DTU.pdf, checked on 11.05.17.

Binnemans, Koen; Jones, Peter Tom; Blanpain, Bart; van Gerven, Tom; Yang, Yongxiang; Walton, Allan; Buchert, Matthias (2013): Recycling of rare earths. A critical review. In Journal of Cleaner Production 51, pp. 1-22. DOI: 10.1016/j.jclepro.2012.12.037.

Blagoeva, Darina; Alves Dias, Patricia; Pavel, Claudiu C.; Marmier, Alain (2016): Assessment of potential bottlenecks along the materials supply chain for the future deployment of low-carbon energy and transport technologies in the EU. Wind power, photovoltaic and electric vehicles technologies, time frame 2015 - 2030. Luxembourg: Publications Office (EUR, Scientific and technical research series, 28192).

BMWi (2014): Gesetz für den Ausbau erneuerbarer Energien. (EEG 2014). Germany. Available online at https://www.erneuerbare-energien.de/EE/Redaktion/DE/GesetzeVerordnungen/eeg_2014.pdf;jsessionid=7568D409B7D07B0D5447BD5F94AE6215?_blob=publicationFil $\mathrm{e} \& \mathrm{v}=7$, checked on 01.03.17.

BMWi (2018a): Energiedaten: Gesamtausgabe. Available online at https://www.bmwi.de/Redaktion/DE/Downloads/Energiedaten/energiedaten-gesamt-pdfgrafiken.pdf?_blob=publicationFile\&v=28, checked on 1/19/2018.

BMWi (2018b): Regulatory environment and incentives for using electric vehicles and developing a charging infrastructure. Federal Ministry for Economics Affairs and Energy. Available online at 
https://www.bmwi.de/Redaktion/EN/Artikel/Industry/regulatory-environment-and-incentives-for-usingelectric-vehicles.html, checked on 9/12/2018.

Briem, Sebastian (2004): Lebenszyklusanalysen ausgewählter zukünftiger Stromerzeugungstechniken. Ein Forschungsvorhaben mit finanzieller Unterstützung des Bundesministeriums für Wirtschaft und Arbeit. Düsseldorf: Verein Deutscher Ingenieure.

BSH (2006): North Sea: Continental Shelf/Exclusive Economic Zone (EEZ). Federal Maritime and Hydrographic Agency. Available online at

http://www.bsh.de/en/Marine_uses/Industry/CONTIS_maps/NorthSeaGermanContinentalShelfExclusive EconomicZone.pdf, checked on 01.03.17.

BSH (2013): Bundesfachplan Offshore für die deutsche ausschließliche Wirtschaftszone der Nordsee 2012 und Umweltbericht. Federal Maritime and Hydrographic Agency. Hamburg and Rostock. Available online at http://www.bsh.de/de/Meeresnutzung/BFO/Dokumente/BSH_BFO-Nordsee2012-

Netzplan_Internet.pdf, checked on 01.03.17.

BSH (2017): Nordsee: Offshore Windparks. Federal Maritime and Hydrographic Agency. Available online at http://www.bsh.de/de/Meeresnutzung/Wirtschaft/CONTISInformationssystem/ContisKarten/NordseeOffshoreWindparksPilotgebiete.pdf, checked on 01.03.17.

Bundesnetzagentur (2017): Erneuerbare Energien - Anlagenregister. Veröffentlichung Anlagenregister August 2014 bis Dezember 2016. Available online at https://www.bundesnetzagentur.de/DE/Sachgebiete/ElektrizitaetundGas/Unternehmen_Institutionen/E rneuerbareEnergien/Anlagenregister/Anlagenregister_Veroeffentlichung/Anlagenregister_Veroeffentlic hungen_node.html;jsessionid=3FA7D7721B01FBAF5F063C5964E9D636, checked on 2/16/2017.

Burd, Harvey; Byrne, Byron; McAdam, R. A.; Houlsby, Guy; Martin, Chris; Beuckelaers, William et al. (2017): Design aspects for monopile foundations: TC209 Workshop - Foundation Design of Offshore Wind Structures.

Bywaters, G.; John, V.; Lynch, J.; Mattila, P.; Norton, G.; Stowell, J. et al. (2004): Northern Power Systems WindPACT Drive Train Alternative Design Study Report; Period of Performance. April 12, 2001 to January 31, 2005.

Caduff, Marloes; Huijbregts, Mark A. J.; Althaus, Hans-Joerg; Koehler, Annette; Hellweg, Stefanie (2012): Wind power electricity: the bigger the turbine, the greener the electricity? In Environmental science \& technology 46 (9), pp. 4725-4733. DOI: 10.1021/es204108n.

Campos, Marcos Flavio de; Rodrigues, Daniel; Castro, Jose Adilson de (2018): Replacement of NdFeB by Ferrite Magnets. In MSF 912, pp. 106-111. DOI: 10.4028/www.scientific.net/MSF.912.106.

Carrascal, Sergio Rodríguez (2014): Life Cycle Assessment. 1 Kwh generated by Gamesa G114-2.0MW Onshore wind farm. With assistance of Gamesa. basque ecodesign center. Available online at http://www.gamesacorp.com/recursos/doc/productos-servicios/aerogeneradores/life-cycle-assesmentg114-20-mw.pdf, checked on 03.04.17.

Carroll, James; McDonald, Alasdair; Dinwoodie, lain; McMillan, David; Revie, Matthew; Lazakis, Iraklis (2017): Availability, operation and maintenance costs of offshore wind turbines with different drive train configurations. In Wind Energy 20 (2), pp. 361-378. DOI: 10.1002/we.2011. 
Carroll, James; McDonald, Alasdair; McMillan, David (2016): Failure rate, repair time and unscheduled O\&M cost analysis of offshore wind turbines. In Wind Energy 19 (6), pp. 1107-1119. DOI: 10.1002/we.1887.

Chaviaropoulos, P.; Sieros, G.; Lekou, D.; Bacharoudis, K.; Tibaldi, C.; Barlas, T. et al. (2015): Deliverable 1-24 PI-based Assessment of the Results of WP2-WP4. Ongoing Integration Action. InnWind.

Cheng, Ming; Zhu, Ying (2014): The state of the art of wind energy conversion systems and technologies: A review. In Energy Conversion and Management 88, pp. 332-347. Available online at http://www.sciencedirect.com/science/article/pii/S0196890414007614, checked on 16.02.17.

Classen, Mischa; Althaus, Hans-Jörg; Blaser, Silvio; Scharnhorst, Wolfram; Tuchschmied, Matthias; Jungbluth, Niels; Faist Emmenegger, Mireille (2009): Life Cycle Inventories of Metals. Final report ecoinvent, No. 10, data v2.1. ecoinvent centre; Swiss Centre for Life Cycle Inventories. EMPA Dübendorf.

Deutsche Windguard (2017): Status des Offshore Windenergieausbaus in Deutschland. With assistance of S. Lüers, A. Wallasch, K. Vogelsang. Varel, Germany. Available online at http://www.windguard.de/_Resources/Persistent/005f7376fe568db6655015912203b4170c0d17c2/Fact sheet-Status-Offshore-Windenergieausbau-2017.pdf, checked on 01.03.17.

DONG Energy (2008): RS 1a: Life cycle approaches to assess emerging energy technologies. With assistance of European Commission (NEEDS New Energy Externalities Developments for Sustainability, 502687), checked on 01.03.17.

D'Souza, Neil; Gbegbaje-Das, Erhi; Shonfield, Peter (2011): Life Cycle Assessment Of Electricity Production from a Vestas V112 Turbine Wind Plant. With assistance of Vestas Wind Systems. PE North West Europe ApS. Copenhagen. Available online at https://www.vestas.com/ /media/vestas/about/sustainability/pdfs/lca_v112_study_report_2011.pdf, checked on 03.04.17.

EAA (2013): Environmental Profile Report for the European Aluminium Industry. Life Cycle Inventory data for aluminium production and transformation processes in Europe. Edited by Walter Klöpffer. European Aluminium Association. Available online at http://european-aluminium.eu/media/1329/environmentalprofile-report-for-the-european-aluminium-industry.pdf, checked on 12.05.17.

EC (2005): Integrated Pollution Prevention and Control. Reference Document on Best Available Techniques in the Smitheries and Foundries Industry. European Commission. Available online at http://eippcb.jrc.ec.europa.eu/reference/BREF/sf_bref_0505.pdf, checked on 12.05.17.

EWEA (2011): UpWind: Design limits and solutions for very large wind turbines. A $20 \mathrm{MW}$ turbine is feasible. Edited by The European Wind Energy Association. Available online at http://www.ewea.org/fileadmin/ewea_documents/documents/upwind/21895_UpWind_Report_low_w eb.pdf, checked on 11.05.17.

Eymann, Lea; Stucki, Matthias; Fürholz, Andreas; König, Alex (2015): Ökobilanzierung von Schweizer Windenergie. Bundesamt für Energie BFE. Bern.

Fraunhofer IEE (2018): Windmonitor. Available online at http://windmonitor.iee.fraunhofer.de/windmonitor_de/, checked on 10.09.18.

Fraunhofer IWES; Fraunhofer IBP; IFEU; Stiftung Umweltenergierecht (2015): INTERAKTION EE-STROM, WÄRME UND VERKEHR. Analyse der Interaktion zwischen den Sektoren Strom, Wärme/Kälte und Verkehr in Deutschland in Hinblick auf steigende Anteile fluktuierender Erneuerbarer Energien im 
Strombereich unter Berücksichtigung der europäischen Entwicklung. Ableitung von optimalen strukturellen Entwicklungspfaden für den Verkehrs- und Wärmesektor. Available online at https://www.iee.fraunhofer.de/content/dam/iwes-

neu/energiesystemtechnik/de/Dokumente/Veroeffentlichungen/2015/Interaktion_EEStrom_Waerme_V erkehr_Endbericht.pdf, checked on 1/19/2018.

Garrett, Peter; Rønde, Klaus (2011): Life Cycle assessment of Electricity Production from a V90-2.0 MW Gridstreamer Wind Plant. With assistance of Vestas Wind Systems. Available online at https://www.vestas.com/ /media/vestas/about/sustainability/pdfs/lca_v902mw_version1.pdf, checked on 03.04.17.

Garrett, Peter; Rønde, Klaus (2013): Life Cycle Assessment of Electricity Production from an Onshore V1002.6 MW Wind Plant. Vestas. Available online at https://www.vestas.com/ /media/vestas/about/sustainability/pdfs/lca_v1002_6mw_version_1_1.pdf, checked on 01.03.17.

Glöser-Chahoud, S.; Kühn, A.; Tercero, Espinoza Luis (2016): Globale Verwendungsstrukturen der Magnetwerkstoffe Neodym und Dysprosium: Eine szenariobasierte Analyse der Auswirkung der Diffusion der Elektromobilität auf den Bedarf an Seltenen Erden. Working Paper Sustainability and Innovation No. S 05/2016. Fraunhofer ISI. Available online at https://www.isi.fraunhofer.de/content/dam/isi/dokumente/sustainability-innovation/2016/WP052016_Globale-Verwendungsstrukturen.pdf.

Graedel, T. E.; Reck, Barbara K. (2016): Six Years of Criticality Assessments. What Have We Learned So Far? In Journal of Industrial Ecology 20 (4), pp. 692-699. DOI: 10.1111/jiec.12305.

Habib, Komal; Wenzel, Henrik (2016): Reviewing resource criticality assessment from a dynamic and technology specific perspective - using the case of direct-drive wind turbines. In Journal of Cleaner Production 112, pp. 3852-3863. DOI: 10.1016/j.jclepro.2015.07.064.

Hamm, Christian; Siegel, Daniel; Niebuhr, Nils; Jurkojc, Piotr; Hellen, Rene von der (2015): Offshore Foundation Based on the ELiSE Method. In Christian Hamm (Ed.): Evolution of Lightweight Structures, vol. 6. Dordrecht: Springer Netherlands (Biologically-Inspired Systems), pp. 195-206.

Henning, H. M.; Palzer, A. (2012): 100 \% erneuerbare Energien für Strom und Wärme in Deutschland. Fraunhofer ISE. Freiburg. Available online at https://www.ise.fraunhofer.de/content/dam/ise/de/documents/publications/studies/studie-100erneuerbare-energien-fuer-strom-und-waerme-in-deutschland.pdf.

Henning, H. M.; Palzer, A. (2015): Was kostet die Energiewende? - Wege zur Transformation des deutschen Energiesystems bis 2050. Fraunhofer ISE.

Iker Marino (2017): SUPRAPOWER. Superconducting light generator for large offshore wind turbines. With assistance of Tecnalia Research \& Innovation, Columbus Superconductors, IEE, Karlsruher Institut Technologie, University of Southampton, D2M Engineering et al. Available online at http://www.suprapower-fp7.eu/docs.php, checked on 12.05.17.

IWCC; ICA (2017): Global 2018 semis end use data set. International Wrought Copper Council; International Copper Association. 
Jensen, Bogi B.; Mijatovic, Nenad; Abrahamsen, Asger B. (2013): Development of superconducting wind turbine generators. In Journal of Renewable and Sustainable Energy 5 (2), p. 23137. DOI:

10.1063/1.4801449.

Jiang, L.; Xiang, D.; Tan, Y. F.; Nie, Y. H.; Cao, H. J.; Wei, Y. Z. et al. (2018): Analysis of wind turbine Gearbox's environmental impact considering its reliability. In Journal of Cleaner Production 180, pp. 846-857. DOI: 10.1016/j.jclepro.2018.01.078.

Lacal-Arántegui, Roberto (2015): Materials use in electricity generators in wind turbines - state-of-the-art and future specifications. In Journal of Cleaner Production 87, pp. 275-283. DOI:

10.1016/j.jclepro.2014.09.047.

Martínez, E.; Sanz, F.; Pellegrini, S.; Jiménez, E.; Blanco, J. (2009): Life cycle assessment of a multi-megawatt wind turbine. In Renewable Energy 34 (3), pp. 667-673. DOI: 10.1016/j.renene.2008.05.020.

Mathew, Sathyajith; Lim, Chee Ming; Petra, Mohammed Iskandar; Philip, Geeta Susan; Noorfathin, Maziyyah; Mathew, Manuel S.; Raj, Veena (2016): Matching the Characteristics of Low Wind Speed Turbines with Candidate Wind Regimes. In Energy Procedia 95, pp. 286-293. DOI:

10.1016/j.egypro.2016.09.071.

Mishnaevsky, Leon; Branner, Kim; Petersen, Helga Nørgaard; beauson, Justine; McGugan, Malcolm; Sørensen, Bent F. (2017): Materials for Wind Turbine Blades. An Overview. In Materials 10 (11). DOI: 10.3390/ma10111285.

Moss, Raymond; Willis, Peter; Tercero, Espinoza Luis; Tzimas, Evangelos; Arendorf, Josephine; Thompson, Paul et al. (2013): Critical metals in the path towards the decarbonisation of the EU energy sector. Assessing rare metals as supply-chain bottlenecks in low-carbon energy technologies. Luxembourg: Publications Office of the European Union (EUR - Scientific and technical research series, EUR 25994).

Myhr, Anders (2016): Developing Offshore Floating Wind Turbines: The Tension-Leg-Buoy Design. Department of Mathematical Sciences and Technology. Faculty of Environmental Science and Technology.

Nitsch, J. (2014): GROKO-II: Szenarien der deutschen Energieversorgung auf der Basis des EEGGesetzentwurfs - insbesondere Auswirkungen auf den Wärmesektor, checked on 1/19/2018.

Oellgaard, Boerge (2003): Method of mounting elements in a wind turbine tower, wind tower suspension unit, system of mutually attachable members. Applied for by Vestas Wind Systems A/S on 2/5/2003. App. no. EP20030709662. Patent no. EP 1472458 B2. Priority no. 06.02.2002.

Ortegon, Katherine; Nies, Loring F.; Sutherland, John W. (2013): Preparing for end of service life of wind turbines. In Journal of Cleaner Production 39, pp. 191-199. DOI: 10.1016/j.jclepro.2012.08.022.

Pathak, Arjun K.; Khan, Mahmud; Gschneidner, Karl A.; McCallum, Ralph W.; Zhou, Lin; Sun, Kewei et al. (2015): Cerium. An unlikely replacement of dysprosium in high performance Nd-Fe-B permanent magnets. In Advanced materials 27 (16), pp. 2663-2667. DOI: 10.1002/adma.201404892.

Penzkofer, A.; Cooke, G.; Odavic, M.; Atallah, K. (2017): Coil Excited Pseudo Direct Drive Electrical Machines. In IEEE Trans. Magn. 53 (1), pp. 1-11. DOI: 10.1109/TMAG.2016.2603966.

Pereg, J. R.; Hoz, J. F. (2013): ECOWIND - Life Cycle Assessment of 1 Kwh generated by a Gamesa onshore wndfarm G90 2.0 MW. Gamesa, checked on 03.04.17. 
Polinder, H.; van der Pijl, F.F.A.; Vilder, G.-J. de; Tavner, P. J. (2006): Comparison of Direct-Drive and Geared Generator Concepts for Wind Turbines. In IEEE Trans. On Energy Conversion 21 (3), pp. 725-733. DOI: 10.1109/TEC.2006.875476.

Polinder, Henk; Ferreira, Jan Abraham; Jensen, Bogi Bech; Abrahamsen, Asger B.; Atallah, Kais; McMahon, Richard A. (2013): Trends in Wind Turbine Generator Systems. In IEEE Journal of Emerging and Selected Topics in Power Electronics 1 (3), pp. 174-185. DOI: 10.1109/JESTPE.2013.2280428.

Prognos AG, EWI, GWS (2014): Entwicklung der Energiemärkte - Energiereferenzprognose. Studie im Auftrag des Bundesministeriums für Wirtschaft und Technologie, checked on 1/19/2018.

Raadal, Hanne Lerche; Vold, Bjørn Ivar; Myhr, Ander; Nygaard, Tor Anders (2014): GHG emissions and energy performance of offshore wind power. In Renewable Energy 66, pp. 314-324. Available online at http://www.sciencedirect.com/science/article/pii/S0960148113006654, checked on 01.03.17.

Rasmussen, Anders Nygaard (2011): Steel tower for a wind turbine. Applied for by Siemens on 11/10/2011. App. no. 13/099.454. Patent no. US 9394879 B2. Priority no. 05.05.2010.

Rippel, K. M.; Wiede, T.; Meinecke, M.; König, R. (2018): Szenriorahmen für den Netzentwicklungsplan Strom 2030 (Version 2019). Entwurf der Übertragungsnetzbetreiber. Available online at https://www.netzentwicklungsplan.de/sites/default/files/paragraphs-files/\%C3\%9CNBEntwurf_Szenariorahmen_2030_V2019.pdf.

Royen, H.; Fortkamp, U. (2016): Rare Earth Elements - Purification, Seperation and Recycling. Stockholm: IVL Swedish Environmental Research Institute Ltd. (No. C 211).

SGRE (2017): Siemens and Gamesa to merge wind businesses to create a leading wind power player. Siemens Gamesa Renewable Energy. Available online at http://www.gamesacorp.com/en/communication/news/siemens-and-gamesa-to-merge-windbusinesses-to-create-a-leading-wind-power-player.html?idCategoria=0\&especifica=0, checked on $3 / 14 / 2018$.

Sheng, Shuangwen (2013): Report on Wind Turbine Subsystem Reliability - A Survey of Various Databases. NREL National Renewable Energy Laboratory.

Sieros, G.; Chaviaropoulos, P.; Sørensen, J. D.; Bulder, B. H.; Jamieson, P. (2012): Upscaling wind turbines. Theoretical and practical aspects and their impact on the cost of energy. In Wind Energ. 15 (1), pp. 3-17. DOI: $10.1002 /$ we. 527.

Sprecher, Benjamin; Xiao, Yanping; Walton, Allan; Speight, John; Harris, Rex; Kleijn, Rene et al. (2014): Life cycle inventory of the production of rare earths and the subsequent production of NdFeB rare earth permanent magnets. In Environmental science \& technology 48 (7), pp. 3951-3958. DOI: 10.1021/es404596q.

Stehouwer, Ewoud; van Jan Zinderen, Gerrit (2016): Deliverable D3.41. Conceptual nacelle designs of 10-20 MW wind turbines. InnWind.

Trabish, Herman K. (2014): Is GE's Space Frame Tower the Future of Wind Power? GE goes back to the roots of wind power-but with a twist. Greentech Media. Available online at https://www.greentechmedia.com/articles/read/Is-GEs-Space-Frame-Wind-Turbine-Tower-The-Futureof-Wind-Power, updated on 3/7/2014, checked on 5/13/2017.

USGS (2009): Mineral Commodity Summaries 2009. U.S. Department of the Interior; U.S. Geological Survey. 
USGS (2017): Mineral Commodity Summaries 2017. U.S. Department of the Interior; U.S. Geological Survey. Virginia. Available online at https://doi.org/10.3133/70180197.

Vestas (2006): Life cycle assessment of electricity produced from onshore sited wind power plants based on Vestas V82-1.65 MW turbines. Denmark, checked on 28.02.17.

Vestas (2012): Rare Earth Elements. Rare Earth Elements from a Life Cycle Assessments perspective. Available online at https://www.vestas.com/ /media/vestas/about/sustainability/pdfs/sustainability\%202011.pdf, checked on 11.05.17.

Viebahn, Peter; Arnold, Karin; Friege, Jonas; Krüger, Christine; Nebel, Arjuna; Samadi, Sascha et al. (2014): KRESSE - kritische mineralische Ressourcen und Stoffströme bei der Transformation des deutschen Energieversorgungssystems. Abschlussbericht. Wuppertal: Wuppertal Institut für Klima, Umwelt, Energie.

Viebahn, Peter; soukup, Ole; Samadi, Sascha; Teubler, Jens; Wiesen, Jens; Ritthoff, Michael (2015): Assessing the need for critical minerals to shift the German energy system towards a high proportion of renewables. In Renewable and Sustainable Energy Reviews 49, pp. 655-671. Available online at http://www.sciencedirect.com/science/article/pii/S1364032115003408, checked on 11.05.17.

Vries, Eize de (2015): Technology 3MW model: Vestas reveals low-wind V136-3.45MW turbine. In Windpower monthly, 2015. Available online at http://www.windpowermonthly.com/article/1365873/technology-3mw-model-vestas-reveals-low-windv136-345mw-turbine, checked on 13.05.17.

Wilburn, D. R. (2011): Wind energy in the United States and materials required for the land-based wind turbine industry from 2010 through 2030. U.S. Geological Survey (Scientific Investigations Report 2011, 5036).

Yang, Yongxiang; Walton, Allan; Sheridan, Richard; Güth, Konrad; Gauß, Roland; Gutfleisch, Oliver et al. (2017): REE Recovery from End-of-Life NdFeB Permanent Magnet Scrap. A Critical Review. In J. Sustain. Metall. 3 (1), pp. 122-149. DOI: 10.1007/s40831-016-0090-4.

Zimmermann, Till; Rehberger, Max; Göling-Reisemann, Stefan (2013): Material Flows Resulting from Large Scale Deployment of Wind Energy in Germany. In Resources 2 (3), pp. 303-334. DOI:

$10.3390 /$ resources 2030303 . 